\title{
Durabilidad del hormigón: Acción de disoluciones de sulfato de calcio $y$ de sulfato de magnesio sobre un cemento portland de alta resistencia inicial. Influencia de la adición de escorias y de cenizas volantes
}

DEMETRIO GASPAR-TEBAR y JOSE LUIS SAGRERA-MORENO. ICCET/CSIC. MADRID
MANUEL AGUANELL-GARCIA. Cementos Valderrivas, S.A. MADRID
VICTORIANO GONZÁLEZ-VILA. Cementos del Atlántico, S.A. SEVILLA
ESPAÑA

Fecha de recepción: 25-V-90

\section{RESUMEN}

En este artículo - que forma parte de un Proyecto de Investigación del ICCET, a largo plazo- se estudia la variación de las resistencias mecánicas, a flexotracción, de las probetas de mortero $(1: 3)$ de $1 \times 1 \times 6 \mathrm{~cm}$ hechas con un cemento portland de alta resistencia inicial y con sus mezclas (cemento/adición $=85 / 15-65 / 35-40 / 60$ y 30/70, en peso) con una escoria de horno alto y una ceniza volante (seleccionadas de entre diversas muestras por sus características) cuando se someten después del período de curado (1 día en cámara húmeda y 21 días bajo agua potable filtrada) a la acción de una disolución saturada de yeso, cuatro disoluciones de sulfato de magnesio con distintas concentraciones $(3,22-32,20-128,80$ y $515,20 \mathrm{~g} / \mathrm{l}$ de $\mathrm{MgSO}_{4} .7 \mathrm{H}_{2} \mathrm{O}$ ), una disolución sat. de yeso con 3,22 $\mathrm{g} / \mathrm{l}$ de $\mathrm{MgSO}_{4} .7 \mathrm{H}_{2} \mathrm{O}$, una disolución saturada de yeso con 32,20 g/l de $\mathrm{MgSO}_{4} .7 \mathrm{H}_{2} \mathrm{O}$ y, además, agua potable filtrada, durante $56-90-180-360-540-720-900$ y 1.080 días.

Los trabajos efectuados han permitido establecer una clasificación de mayor a menor, de acuerdo con el comportamiento mecánico-resistente, a flexotracción, del cemento 1 y de las mezclas cemento 1/escoria y cemento 1/ceniza volante frente a las mencionadas disoluciones agresivas.

\section{SUMMARY}

This article -included on a long time ICCET Investigation Program- studies the mechanical resistances variation to flexure, of the $1 \times 1 \times 6 \mathrm{~cm}$ mortar samples $(1: 3)$ made with high initial resistance cement and with several slags addition (cement/slag $=85 / 15-65 / 35-40 / 60$ and 30/70) with high furnace slag and a fly ash (with selected characteristies) when they were submited after the cured period (1 day at $100 \%$ R.H. and 21 days inside filtered potable water) to the action of the gypsum saturated solution, four magnesium sulphate solutions with the next concentrations $(3.22-32.20-128.80$ and $515.20 \mathrm{~g} / \mathrm{l}$ of $\mathrm{MgSO}_{4} .7 \mathrm{H}_{2} \mathrm{O}$ ), gypsum saturated solution with $3.22 \mathrm{~g} / \mathrm{l}$ $\mathrm{MgSO}_{4} .7 \mathrm{H}_{2} \mathrm{O}$ a gypsum saturated solution with $32.20 \mathrm{~g} / \mathrm{l}$ $\mathrm{MgSO}_{4} .7 \mathrm{H}_{2} \mathrm{O}$ and, moreover, filtered potable water, during $56-90-180-360-540-720-900$ and 1.080 days. The results obtained have produced a clasification accord to the mechanical behaviour to flexure of the cement $n .{ }^{\circ} 1$ and the mixed cement $n .01 /$ slag and cement n.0 1/fly ash front to the agressive solutions mentioned.

\section{PALABRAS CLAVE:}

DURABILIDAD HORMIGÓN-ACCIÓN DISOLUCIONES YESO Y SULFATO MAGNESIO; CEMENTOSESCORIAS-CENIZAS VOLANTES.

\section{INTRODUCCIÓN}

El comportamiento de los morteros y hormigones sometidos a la acción de diferentes medios agresivos ha sido objeto de numerosos trabajos como consecuencia del gran número de obras construidas en dichos medios, siendo un tema que ha preocupado y preocupa no solo desde un punto de vista constructivo, sino científico, para conocer las causas que producen el ataque químico y utilizar los materiales idóneos en cada caso; de aquí, que con objeto de ampliar el conocimiento del mecanismo de las reacciones que tienen lugar cuando los cementos portland hidratados, y sobre todo de sus mezclas con adiciones naturales y artificiales, se someten a la acción de 
disoluciones agresivas se haya realizado este trabajo, que forma parte de un Programa de Investigación del ICCET a desarrollar a largo plazo, tanto a escala de laboratorio como real (1).

Dentro de las disoluciones agresivas, además de las correspondientes a la disolución saturada de yeso y al agua de mar, se ha dado preferencia a las disoluciones a base de sulfato de magnesio - por encontrarse en determinadas aguas y terrenos españoles- cuyas concentraciones cubriesen un espectro amplio, en presencia de otros cationes [en este caso el Ca (II)].

En otros trabajos (2) (3) (4) se ha estudiado el comportamiento de un cemento portland industrial de alta resistencia inicial, análogo al de la presente comunicación, cuando se somete a la acción del agua desionizada, de una disolución de sulfato de sodio y de otra de sulfato de magnesio, que atraviesan los lechos granulados fabricados con dicho cemento una vez hidratado y curado. Asimismo, en (5) (6) (7) (8) se ha estudiado la influencia de la adición de escoria al cemento mencionado cuando las probetas de mortero $(1: 3)$ de $1 \times 1 \times 6 \mathrm{~cm}$ se someten -durante diversos períodos de tiempo- a la acción del agua de mar artificial ASTM D1141-75 y del agua potable filtrada, habiendo determinado la evolución de las resistencias mecánicas a flexotracción, las características estructurales de las nuevas fases sólidas formadas y de las fracciones enriquecidas (cemento hidratado y cemento hidratadoatacado) por DRX, así como las modificaciones de la concentración iónica que han experimentado los medios en donde han estado sumergidas las probetas de mortero.

Para realizar este trabajo se seleccionaron tres cementos portland industriales de características estructurales distintas, una escoria siderúrgica y tres cenizas volantes (elegidas por sus características de entre 15 muestras distintas, de otras tantas centrales termoeléctricas españolas). Los resultados obtenidos serán objeto de otras publicaciones.

\section{PARTE EXPERIMENTAL}

En este trabajo se da cuenta de los resultados obtenidos cuando las probetas de mortero (1:3) de $1 \times 1 \times 6 \mathrm{~cm}$ hechas con un cemento portland industrial de alta resistencia inicial (cemento 1) y con sus mezclas cemento $1 /$ escoria granulada de alto horno y cemento $1 /$ ceniza volante $(E N-1)=85 / 15$ - 65/35 $40 / 60$ y $30 / 70$, en peso, se someten a la acción de las disoluciones agresivas que se mencionan en 2.1.4 y, además, agua potable filtrada, durante los periodos de tiempo que se indican en 2.2.1, después del período de curado ( 24 horas en cámara húmeda y, a continuación, bajo agua potable filtrada, a $20 \pm 2^{\circ} \mathrm{C}$, durante 21 dias).

\subsection{Materiales utilizados}

\subsubsection{Cemento}

Se ha utilizado un cemento portland industrial, de alta resistencia inicial, que se ha designado cemento 1 , cuya composición química y potencial calculada (Bogue), así como la superficie especifica se encuentra en la tabla 1.

En la figura 1 se incluyen los DRX del cemento $y$ del residuo insoluble en ácido salicílicometanol (zonas de las fases cristalinas correspondientes a los aluminatos).

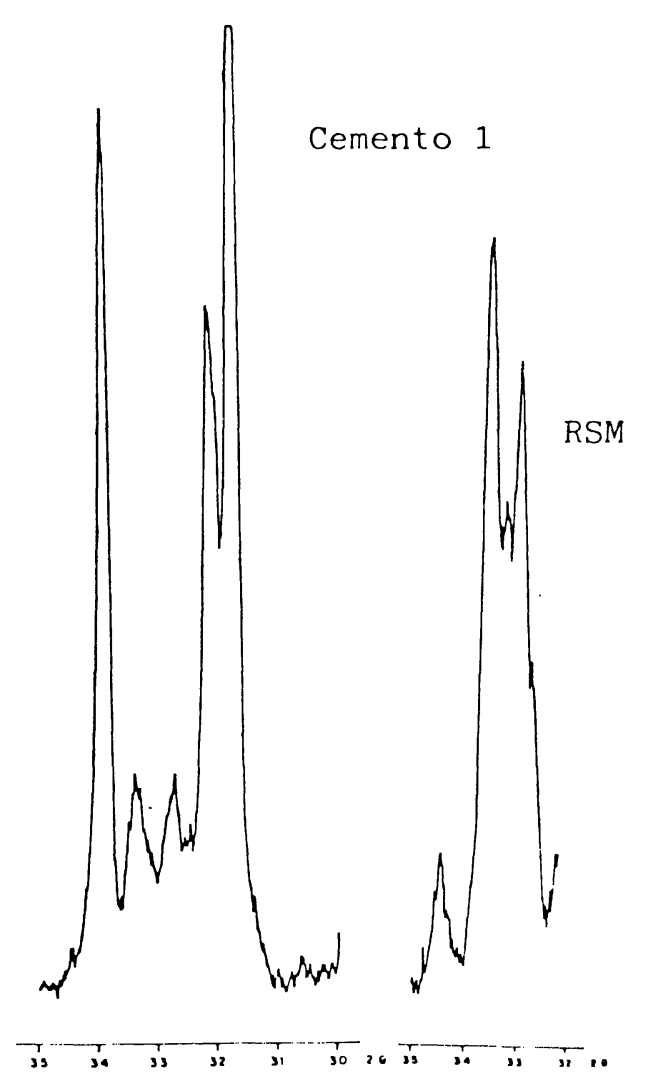

Fig. 1.-DRX del cemento 1 y del RSM.

\subsubsection{Adiciones}

De entre las adiciones estudiadas, en una primera etapa, se han seleccionado la escoria de horno alto y la ceniza volante, que se reseñan a continuación. 


\subsubsection{Escoria}

Se ha empleado la escoria granulada de horno alto, cuyo análisis químico y difractograma de rayos $X$ se encuentran en la tabla 1 y en la figura 2.

TABLA 1

Análisis químico (\% en masa), composición potencial y superficie específica

\begin{tabular}{|c|c|c|c|}
\hline Determinaciones & Cemento 1 & Escoria & $\begin{array}{r}\text { Ceniza } \\
\text { Volante } \\
\text { EN - I } \\
\end{array}$ \\
\hline Pérdida por calcinación & 0,4 & 0,4 & 2,8 \\
\hline Residuo insoluble & 3,1 & 0,0 & 0,2 \\
\hline Dióxido de silicio, $\mathrm{SiO}_{2}$ & 19,3 & 35,2 & 46,1 \\
\hline Oxido de hierro (III), $\mathrm{Fe}_{2} \mathrm{O}$ & 3,9 & 0,7 & 6,9 \\
\hline Oxido de aluminio, $\mathrm{Al}_{2} \mathrm{O}_{3}$ & 6,2 & 17,0 & 36,4 \\
\hline Oxido de calcio, $\mathrm{CaO}$ & 61,1 & 37,3 & 4,1 \\
\hline Oxido de Magnesio, Mg $\mathrm{O}$ & 1,5 & 6,3 & 1,9 \\
\hline Trióxido de azufre, $\mathrm{SO}_{3}$ & 4,1 & 0,0 & 1,0 \\
\hline Manganeso (II) & n.d. & 0,8 & n.d. \\
\hline Suma & 99,6 & 97,7 & 99,4 \\
\hline Ca O libre & 1,0 & - & - \\
\hline n. d. = no determinado & & & \\
\hline \multicolumn{4}{|c|}{ Composición potencial (Bogue) } \\
\hline $\mathrm{C}_{3} \mathrm{~s}$ & 39,2 & & \\
\hline $\mathrm{C}_{2} \mathrm{~s}$ & 25,7 & & \\
\hline $\mathrm{C}_{3} \mathrm{~A}$ & 9,9 & & \\
\hline $\mathrm{C}_{4} \mathrm{AF}$ & 12,0 & & \\
\hline \multicolumn{4}{|c|}{ Superficie especifica (Blaine) } \\
\hline $\mathrm{cm}^{2} / \mathrm{g}$ & 5.313 & & \\
\hline
\end{tabular}

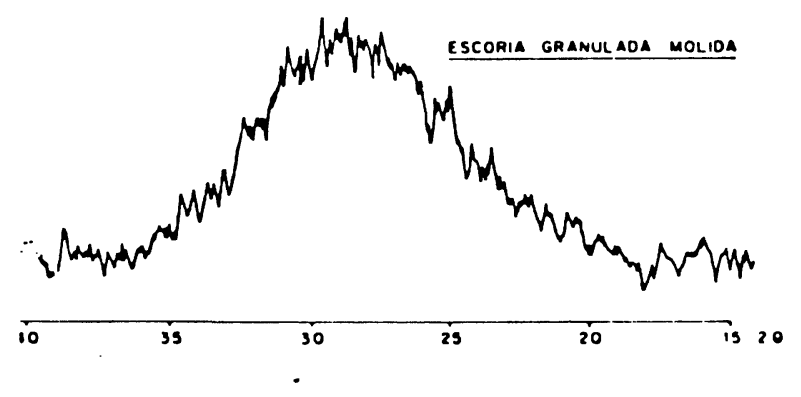

Fig. 2.-DRX de la escoria granulada.

\subsubsection{Ceniza volante}

Se han usado tres cenizas volantes (seleccionadas a partir de 15 muestras distintas de otras tantas centrales térmoeléctricas españolas); de los resultados obtenidos con dichas cenizas volantes - únicamente- se da cuenta en este trabajo de los correspondientes a una de ellas por su procedencia y características, que se ha designado C.V. (EN-1). Su composición química y diagrama de rayos $X$ se encuentran en la tabla 1 y en la figura 3.

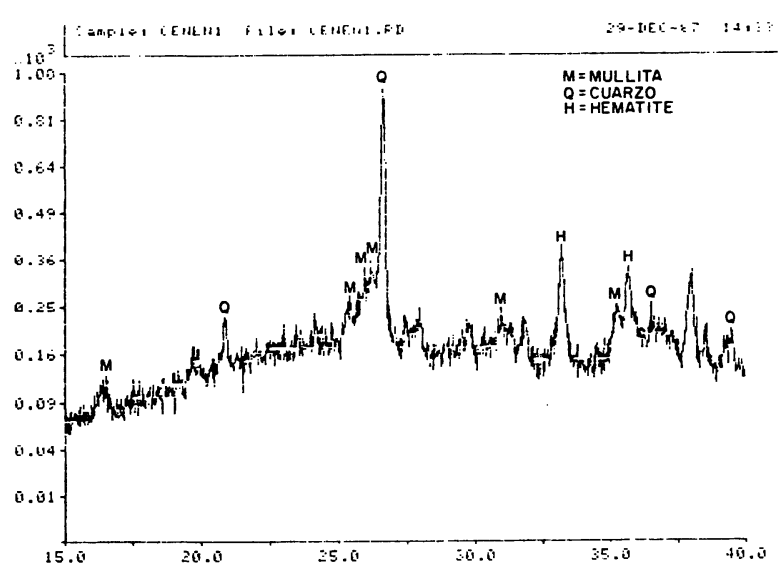

Fig. 3.-DRX de la ceniza volante EN-1.

\subsubsection{Arena}

Para fabricar las probetas de mortero $(1: 3)$ de $1 \times 1 \times 6 \mathrm{~cm}$ se ha usado la arena natural (El Espirdo-Segovia) análoga a la empleada para preparar los morteros normalizados (RC-75), con un contenido de $\mathrm{SiO}_{2}$ superior al $99 \%$. El tamaño de grano está comprendido entre 1 y $1,5 \mathrm{~mm}$.

\subsubsection{Disoluciones agresivas}

Como medios agresivos se han utilizado una disolución saturada de sulfato de calcio hidratado (dis. saturada de yeso), cuatro disoluciones de sulfato de magnesio y dos disoluciones saturadas de sulfato de calcio dihidratado (dis. saturada de yeso) con sulfato de magnesio. Las cantidades disueltas de las sustancias Q.P. y la concentración de los iones $\mathrm{SO}_{4}$ (II), $\mathrm{Mg}$ (II) y Ca (II), en $\mathrm{g} / \mathrm{l}$, figuran en la tabla 2;

TABLA 2

Disoluciones agresivas utilizadas

\begin{tabular}{|c|c|c|c|c|c|}
\hline Disolución & \begin{tabular}{|c|} 
Saturada \\
$\mathrm{Ca} \mathrm{SO}$ \\
4
\end{tabular} & $\begin{array}{c}\mathrm{Mg} \mathrm{SO}_{4} \cdot 7 \mathrm{H}_{2} \mathrm{O} \\
g / 1\end{array}$ & $\begin{array}{c}\mathrm{SO}_{4} \text { (II) } \\
\mathrm{g} / 1\end{array}$ & $\begin{array}{l}\mathrm{Mg} \text { (II) } \\
\mathrm{g} / \mathrm{I}\end{array}$ & $\begin{array}{l}\mathrm{Ca} \text { (II) } \\
\mathrm{g} / 1\end{array}$ \\
\hline 1 & si & - & 1,010 & - & 0,420 \\
\hline 2 & - & 3,22 & 1,263 & 0,318 & - \\
\hline 3 & - & $32, ? 0$ & $12,6,30$ & 3,180 & - \\
\hline 4 & - & 128,80 & 50,200 & $1 ?, 720$ & - \\
\hline 5 & - & 515,20 & 200,800 & 50,880 & - \\
\hline 6 & $\mathrm{si}$ & $3, ? 2 ?$ & 2,273 & 0,318 & $(0,4.20$ \\
\hline 7 & si & 32,20 & $13,6,40)$ & 3,180 & $0,4: 0$ \\
\hline $\begin{array}{l}\text { O (aguat } \\
\text { potable } \\
\text { filtrada) }\end{array}$ & - & - & 0,0003 & 0.0016 & $\left(1,()()^{r}\right.$, \\
\hline
\end{tabular}


además se ha utilizado agua potable filtrada (Canal Isabel II - Madrid) como medio de curado de las diversas series de probetas de mortero y de conservación de las series correspondientes para utilizarlas como testigo.

Para seleccionar la concentración de la disolución de sulfato de magnesio (disolución 2), se ha partido de la correspondiente a los iones $\mathrm{SO}_{4}$ (II) de la disolución saturada de $\mathrm{CaSO}_{4} .2 \mathrm{H}_{2} \mathrm{O}$ (disolución 1) y para las restantes disoluciones de múltiplos de la mencionada disolución $2(\mathrm{~g} / \mathrm{l}=\mathrm{A})$; 10.A (disolución 3), 40.A (disolución 4) y 160.A (disolución 5).

\subsection{Preparación, curado y conservación de las probetas de mortero}

\subsubsection{Probetas de mortero de $1 \times 1 \times 6 \mathrm{~cm}$}

Con el cemento 1 y con las mezclas cemento $1 /$ escoria y cemento $1 / \mathrm{C} . \mathrm{V}$. $(\mathrm{EN}-1)=85 / 15$ $65 / 35$ - 40/60 y 30/70 (en peso), se han preparado las distintas series de probetas de mortero (1:3) de $1 \times 1 \times 6 \mathrm{~cm}(12$ probetas/ 1 serie) como se señala en (9), habiendo utilizado la relación $a / c=0,6$. Las probetas se han curado 1 día en cámara húmeda (a $20 \pm 1^{\circ} \mathrm{C}$, con humedad relativa superior a $90 \%$ y, a continuación, bajo agua potable filtrada (a $20 \pm 2^{\circ} \mathrm{C}$ ) durante 21 días; posteriormente, se han sumergido 12 probetas/1 serie/cemento 0 mezcla/1 edad en $800 \mathrm{ml}$ de agua potable filtrada y de cada una de las disoluciones, en donde han permanecido hasta el momento de su rotura $(56,90,180,360,540,780,900$ y 1.080 dias). Se han preparado, para el trabajo del que se da cuenta en esta comunicación, 576 series de probetas ( 12 probetas/ 1 serie $X$ $\times 576=6.912$ probetas). Los depósitos con las disoluciones y las probetas se han situado en un laboratorio, a $20 \pm 2^{\circ} \mathrm{C}$.

\section{RESULTADOS OBTENIDOS}

\subsection{Evolución de las resistencias mecánicas}

\subsubsection{Sistemas: cemento 1-Agua potable filtrada y disoluciones agresivas}

En la figura 4 se han representado los valores de las resistencias mecánicas, a flexotracción, $\left(\mathrm{kp} / \mathrm{cm}^{2}\right)$ de las series de probetas de mortero (1:3) hechas con el cemento 1 (valores medios de 12 probetas por serie y por edad), sumergidas en las disoluciones $1,2,3,6$ y 7 y en agua potable filtrada, en función del tiempo de conservación hasta 3 años. En dicha figura se aprecia que:
1) Las resistencias mecánicas, a flexotracción, de las diversas series de probetas de mortero sumergidas en la dis. saturada de yeso (excepto las correspondientes a 90 días), así como en la disolución $2(3,22$ $\mathrm{g} / \mathrm{l}$ de $\mathrm{MgSO}_{4} .7 \mathrm{H}_{2} \mathrm{O}$ ), son superiores que las de las series análogas conservadas en agua potable filtrada. Los valores más altos corresponden a las probetas que han estado en la disolución 2.

2) Las resistencias mecánicas, a flexotracción, de las series de probetas sumergidas en la disolución 6 (sat. de yeso $+3,22$ $\mathrm{g} / \mathrm{l}$ de $\mathrm{MgSO}_{4} .7 \mathrm{H}_{2} \mathrm{O}$ ) son mayores que las de las series conservadas bajo agua potable filtrada hasta la edad de 360 dias; a partir de esta edad -y hasta 36 mesesson ligeramente inferiores y ambas siguen un hábito análogo.

3) Las resistencias mecánicas, a flexotracción, de las series de probetas sumergidas en las disoluciones $3(32,20 \mathrm{~g} / \mathrm{l}$ de $\mathrm{MgSO}_{4} .7 \mathrm{H}_{2} \mathrm{O}$ ) y 7 (sat. de yeso $+32,20$ $\mathrm{g} / \mathrm{l}$ de $\mathrm{MgSO}_{4} .7 \mathrm{H}_{2} \mathrm{O}$ ), cuyos valores son muy parecidos, son menores que las correspondientes a las series de probetas análogas conservadas en agua potable filtrada, produciéndose una disminución conforme se incrementa el tiempo de conservación, que tiende a estabilizarse a partir de 30 meses. Los valores que han pasado de $73,9 / 70,3 \mathrm{Kp} / \mathrm{cm}^{2}$ (a 56 días) a $41,2 / 41,4 \mathrm{Kp} / \mathrm{cm}^{2}$ (a 36 meses), han experimentado un descenso del 41 al $44 \%$.

4) Las probetas de mortero sumergidas en las disoluciones 4 y $5(128,80$ y 515,20 $\mathrm{g} / \mathrm{l}$ de $\mathrm{MgSO}_{4} .7 \mathrm{H}_{2} \mathrm{O}$ ) se han fisurado $\mathrm{y}$ roto, como se puede apreciar en las fotografías 1 y 2 . Se ha producido un ataque superficial en el caso de la disolución 5 , desde la primera edad (fotografía 2), y un precipitado superficial y ataque por las aristas (fotografía 1).

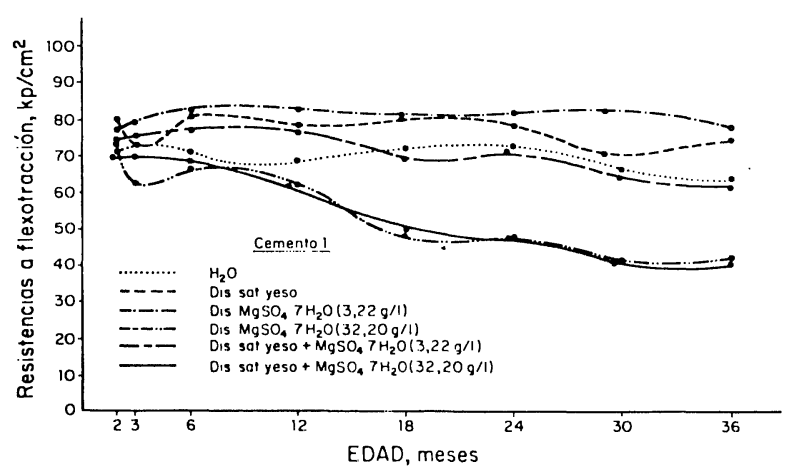

Fig. 4.-Sistemas: Cemento 1 - Dis. agresivas. Evolución de las resistencias mecánicas, a flexotracción. 

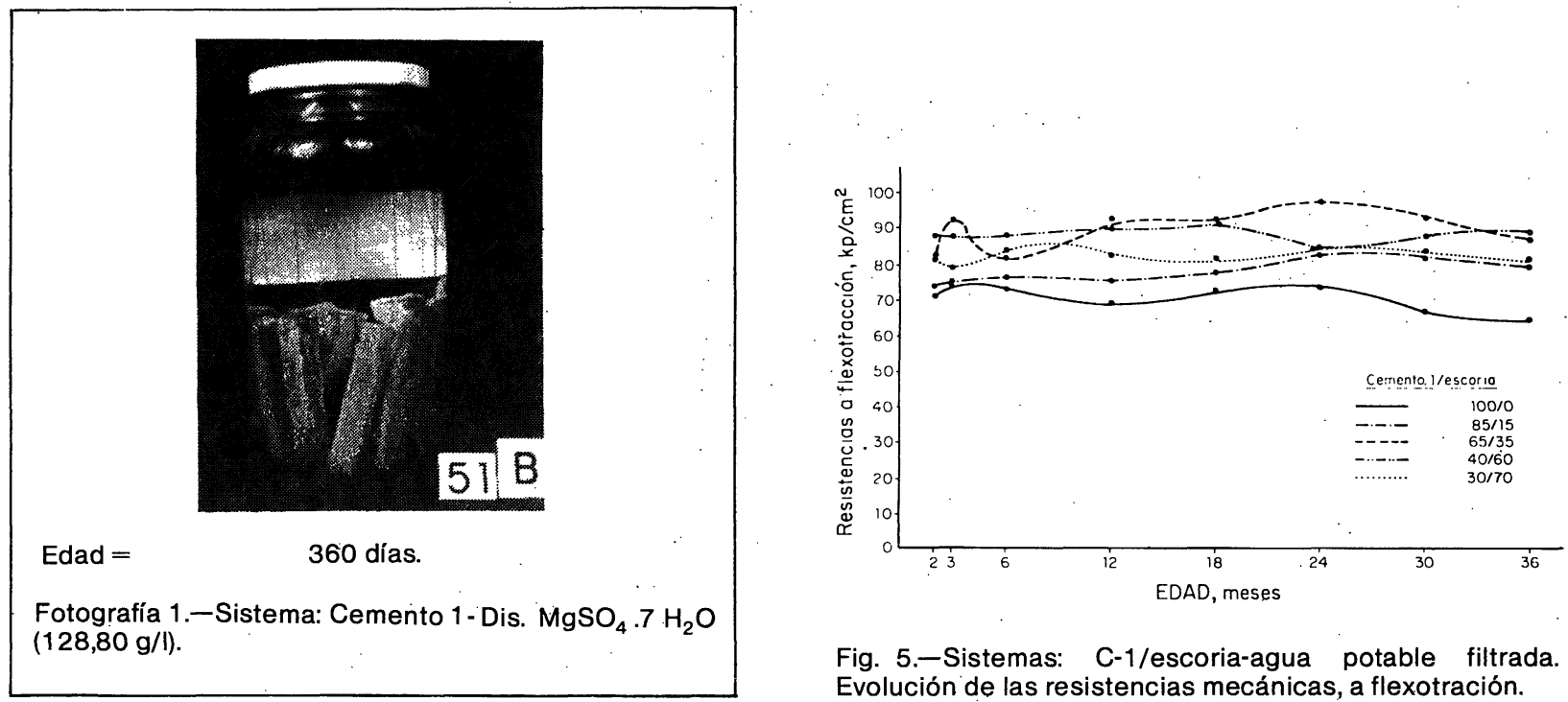

Fig. 5.-Sistemas: C-1/escoria-agua potable filtrada. Evolución de las resistencias mecánicas, a flexotración.

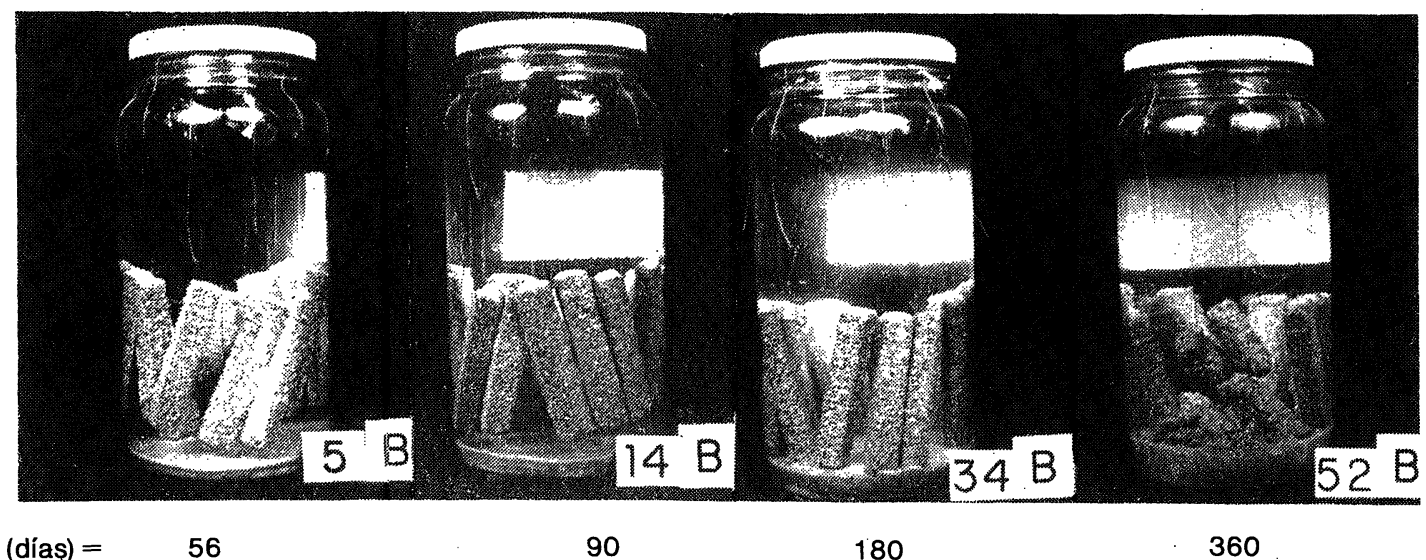

Fotografía 2.-(Fot. 2.1. a 2.4.). Sistema: cemento 1 - Dis. $\mathrm{MgSO}_{4} .7 \mathrm{H}_{2} \mathrm{O}(515,20 \mathrm{~g} / \mathrm{l})$.

De aquí que se establezca desde un punto de vista mecánico-resistente, a flexotracción, de acuerdo con los valores obtenidos, la siguiente clasificación de las probetas de mortero - hechas con el cemento 1- frente a las disoluciones agresivas:

Dis. $2>$ Dis. $1>$ Dis. $0>$ Dis. $6>$ Dis. $3>$ $>$ Dis. $7>$ Dis. $4>$ Dis. 5

\subsubsection{Sistemas: Cemento 1/escoria-agua potable filtrada y disoluciones agresivas}

\subsubsection{Sistemas: cemento 1/escoria-agua potable filtrada}

En la figura 5 se han representado los valores de las resistencias mecánicas, a flexotracción,
$\left(\mathrm{Kp} / \mathrm{cm}^{2}\right)$ de las probetas de mortero (1:3) de $1 \times 1 \times 6 \mathrm{~cm}$ (valores medios de 12 probetas, por serie y por edad) - hechas con el cemento 1 y con las mezclas cemento 1 /escoria mencionadas en 2.2.1- en función del tiempo de conservación (hasta 3 años) en agua potable filtrada.

En dicha figura se aprecia que la adición de escoria favorece en todos los casos estudiados el comportamiento mecánico-resistente de las probetas de mortero hechas con el cemento 1 , sumergidas en agua potable filtrada, durante los períodos de tiempo señalados en 2.2.1. Los valores más altos corresponden a las series de probetas elaboradas con la mezcla cemento $1 /$ escoria $=65 / 35$ (en peso), seguidos de los de las series de las mezclas cemento $1 /$ escoria $=40 / 60-30 / 70$ y $85 / 15$ (en peso). 
De acuerdo con los valores obtenidos se puede establecer la siguiente escala, según el comportamiento mecánico-resistente, a flexotracción:

$$
\begin{gathered}
\text { cemento } 1 / \text { escoria }=65 / 35>40 / 60> \\
>30 / 70>85 / 15>100 / 0
\end{gathered}
$$

\subsubsection{Sistemas: Cemento 1/escoria- disolución saturada de yeso}

En la figura 6 se han representado los valores de las resistencias mecánicas, a flexotracción, $\left(\mathrm{Kp} / \mathrm{cm}^{2}\right)$ de las probetas de mortero $(1: 3)$ de $1 \times 1 \times 6 \mathrm{~cm}$ (valores medios de 12 probetas, por serie y por edad) - hechas con el cemento 1 y con sus mezclas con la escoria indicadas en 2.2.1, sumergidas en la disolución 6 (dis. saturada de yeso) - en función del tiempo de conservación-ataque (hasta 3 años).

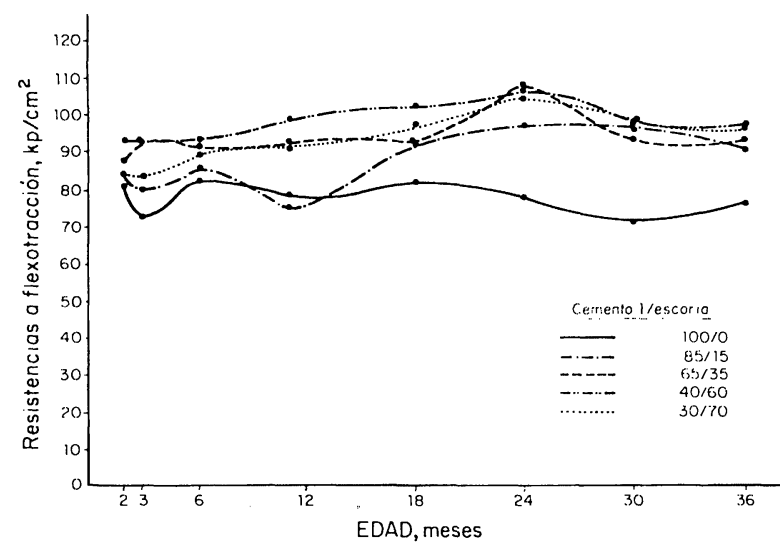

Fig. 6.-Sistemas: C-1/escoria - Dis. saturada de yeso Evolución de las resistencias mecánicas, a flexotracción.

La adición de escoria (en las cantidades estudiadas que se indican en 2.2.1) favorece el comportamiento mecánico-resistente, a flexotracción, de las probetas de mortero hechas con el cemento 1 frente a una disolución saturada de yeso, excepto para las probetas elaboradas con la mezcla que tiene $15 \%$ de escoria (en peso) para la edad de 360 días.

Los valores más altos de las mencionadas resistencias corresponden a las series de probetas fabricadas con la mezcla que tiene $60 \%$ (en peso) de escoria, habiendo experimentado un incremento superior al $30 \%$ a partir de los 6 meses. A la vista de los resultados obtenidos se puede establecer la siguiente escala, de acuerdo con el comportamiento mecánico-resistente, a flexotracción: cemento 1/escoria = $=40 / 60>30 / 70>65 / 35>85 / 15>100 / 0$, en donde se aprecia que las series de probe- tas hechas con las mezclas que tienen los mayores contenidos de escoria $(60$ y $70 \%$, en peso) presentan, frente a una disolución saturada de yeso, las resistencias a flexotracción más elevadas.

3.1.2.3. Sistemas: cemento 1/escoria-disoluciones de sulfato de magnesio

En las figuras 7 y 8 se han representado las resistencias mecánicas, a flexotracción, $\left(\mathrm{Kp} / \mathrm{cm}^{2}\right)$ de las probetas de mortero $(1: 3)$ de $1 \times 1 \times 6 \mathrm{~cm}$ (valores medios de 12 probetas, por serie y por edad) - hechas con el cemento 1 y con las mezclas cemento 1/escoria señaladas en 2.2.1, sumergidas en la disolución 2 (tiene $3,22 \mathrm{~g} / \mathrm{l}$ de $\mathrm{MgSO}_{4} .7 \mathrm{H}_{2} \mathrm{O}$ ) y en la disolución 3 (tiene $32,20 \mathrm{~g} / \mathrm{l}$ de $\mathrm{MgSO}_{4} .7 \mathrm{H}_{2} \mathrm{O}$ ), respectivamente- en función del tiempo de conservación-ataque (hasta 3 años).

a) Sistemas: cemento 1/escoria-disolución 2 $\left(3,22 \mathrm{~g} / \mathrm{l}\right.$ de $\left.\mathrm{MgSO}_{4} .7 \mathrm{H}_{2} \mathrm{O}\right)$

En la figura 7 se puede observar que, como en los sistemas del apartado 3.1.2.3, la adición de escoria favorece el comportamiento mecánico-resistente, a flexotracción, de las probetas de mortero hechas con el cemento 1 cuando se someten a la acción de una disolución de $\mathrm{MgSO}_{4} .7 \mathrm{H}_{2} \mathrm{O}(3,22 \mathrm{~g} / \mathrm{I})$, que tiene una concentración de iones $\mathrm{SO}_{4}$ (II) $=1,263$ $\mathrm{g} / \mathrm{I}$ y de $\mathrm{Mg}(\mathrm{II})=0,318 \mathrm{~g} / \mathrm{l}$, durante los periodos de tiempo mencionados en 2.2.1. De acuerdo con los valores obtenidos se puede establecer, según el comportamiento mecánico-resistente a flexotracción, la siguiente escala: cemento $1 /$ escoria $=40 / 60>65 / 35>30 /$ $170>85 / 15>100 / 0$. En estos sistemas, de un modo parecido a los dos anteriores -en los que la concentración de iones $\mathrm{SO}_{4}$ (II) es 1,263 y $1,010 \mathrm{~g} / \mathrm{l}$, respectivamente- las series

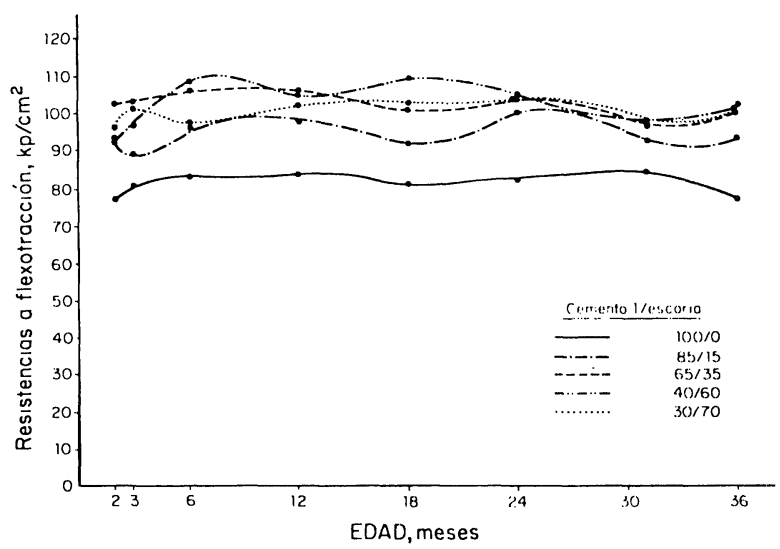

Fig. 7.-Sistemas: C-1/escoria-Dis. $\mathrm{MgSO}_{4} .7 \mathrm{H}_{2} \mathrm{O}(3,22$ $\mathrm{g} / \mathrm{I})$. Evolución de las resistencias mecánicas, a flexotracción. 
de probetas hechas con las mezclas que tienen los mayores contenidos de escoria $160 \%$, en peso, para todas las edades; $70 \%$, en peso, para las cuatro últimas edades y $35 \%$, en peso, para las cuatro primeras edades) presentan las resistencias mecánicas a flexotración más elevadas.

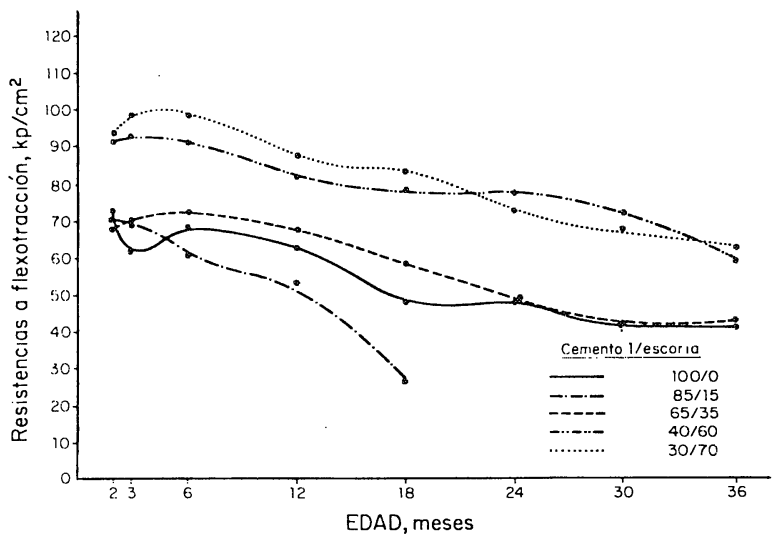

Fig. 8.-Sistemas: C-1/escoria - Dis. $\mathrm{MgSO}_{4} .7 \mathrm{H}_{2} \mathrm{O}(32,20$ $\mathrm{g} / \mathrm{l})$. Evolución de las resistencias mecánicas, a flexotracción. b) Sistemas: cemento 1/escoria-disolución 3 $\left(32,20 \mathrm{~g} / \mathrm{l}\right.$ de $\left.\mathrm{MgSO}_{4} .7 \mathrm{H}_{2} \mathrm{O}\right)$

En la figura 8 se aprecia que las resistencias mecánicas, a flexotracción, de las distintas series de probetas de mortero $(1: 3)$ experimentan un descenso conforme aumenta el tiempo

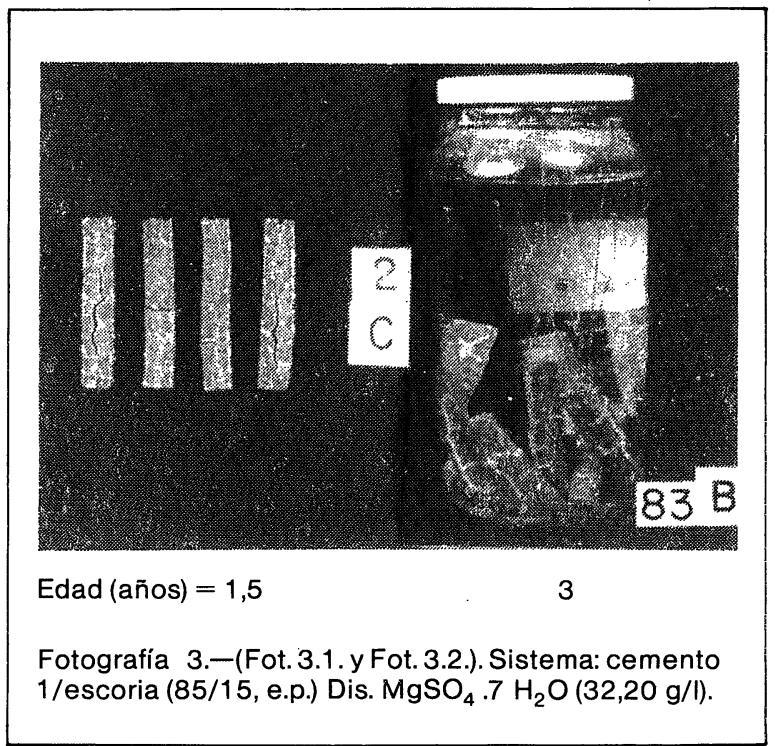

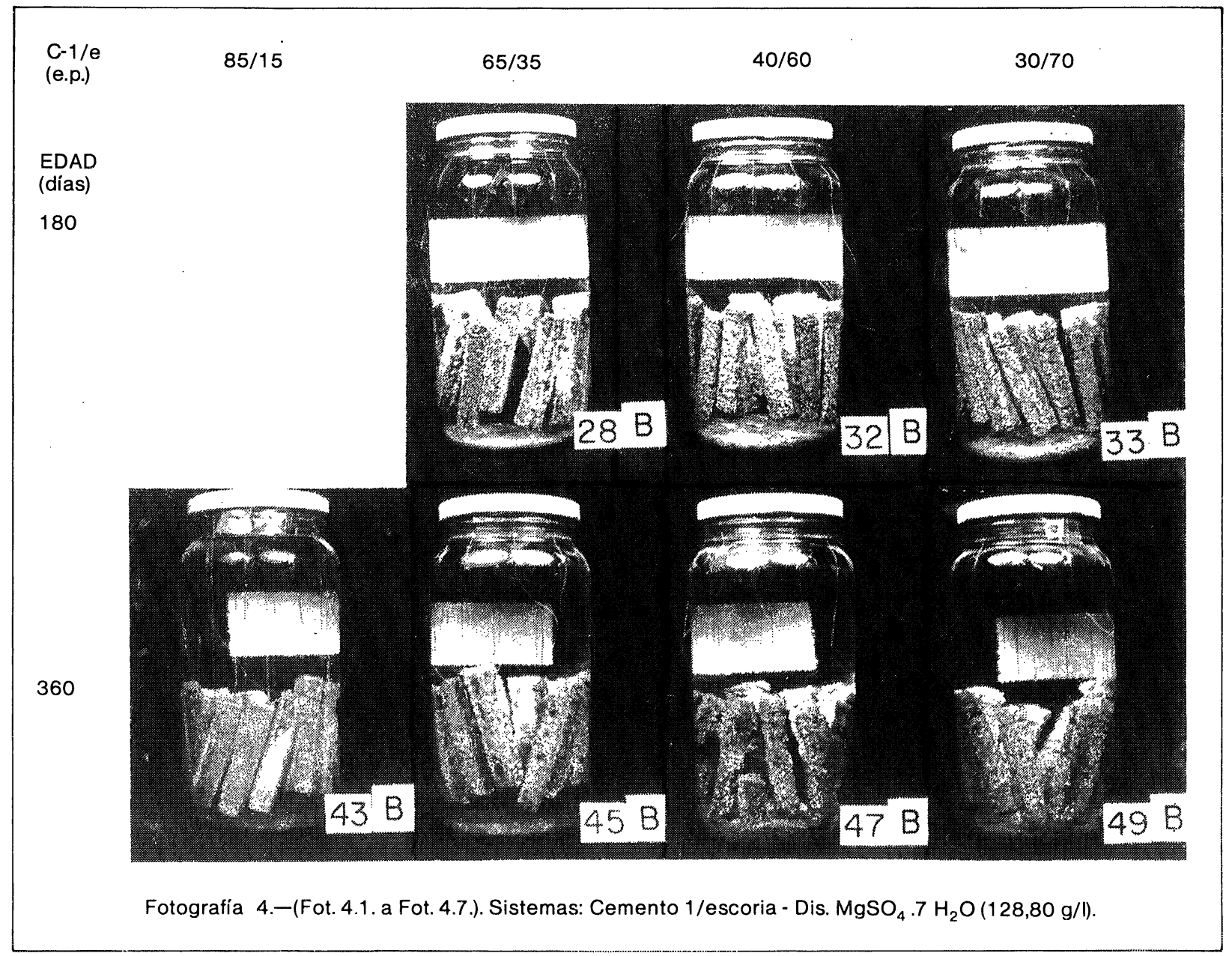




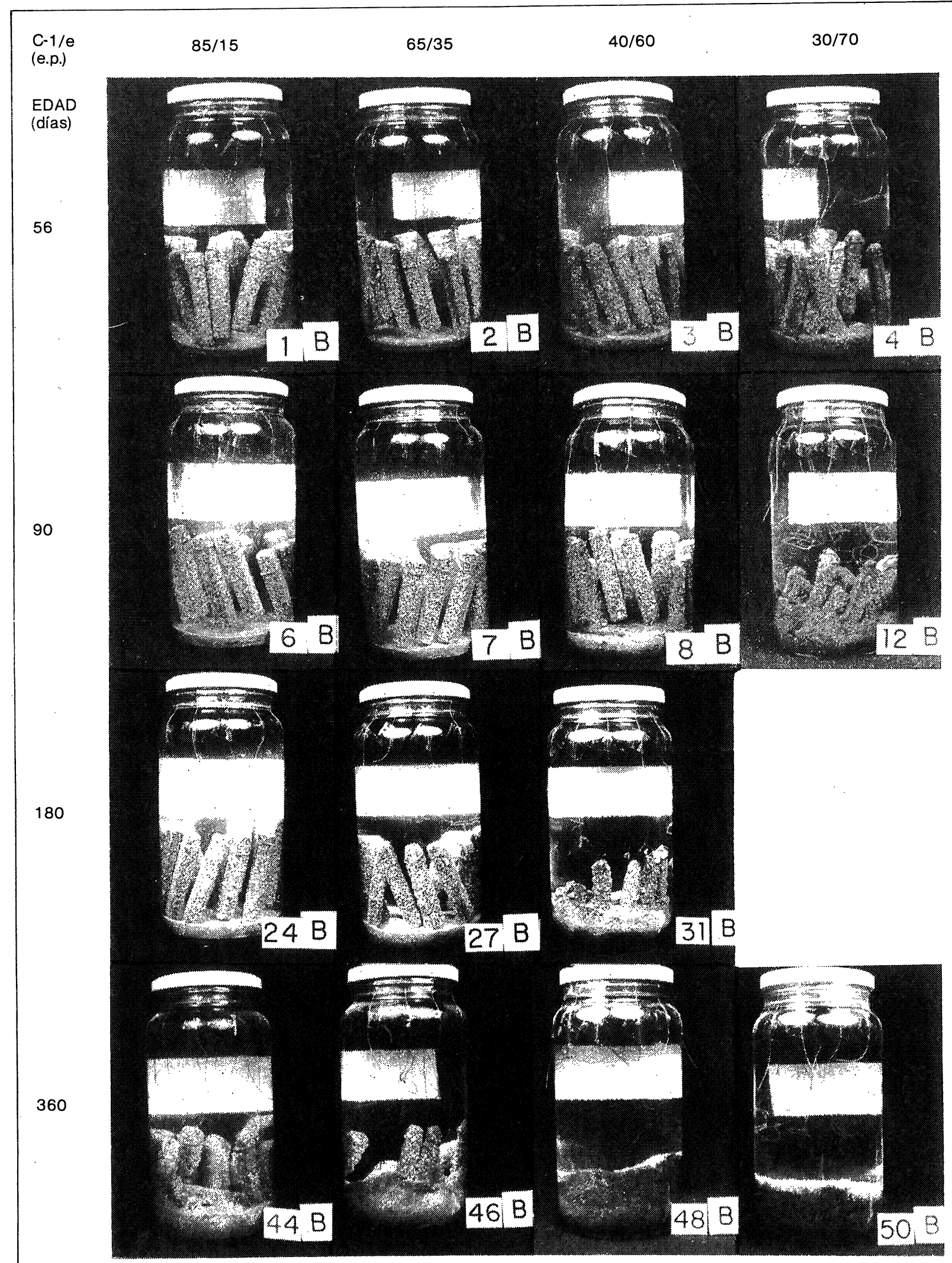

Fotografia 5.-(Fot. 5.1. a Fot. 5.15.). Sistemas: Cemento 1/escoria - Dis. $\mathrm{MgSO}_{4} .7 \mathrm{H}_{2} \mathrm{O}(515,20 \mathrm{~g} / \mathrm{l})$. 
de conservación-ataque (para las series correspondientes al cemento 1 y a la mezcla que tiene $35 \%$ en peso, de escoria dicho descenso -que es del $35 \%$ - se extiende desde la primera edad hasta la de 30 meses, cuyos valores son del mismo orden que la de 36 meses) y que las probetas elaboradas con la mezcla cemento $1 /$ escoria $=85 / 15$, en peso, aparecen agrietadas a la edad de 18 meses (fotografía 3) y -además- deformadas y con un precipitado blanco en las grietas, que se está estudiando, a edades posteriores. Asimismo, las probetas hechas con cemento $1 \mathrm{y}$ con la mezcla cemento $1 /$ escoria $=65 / 35$, en peso, se han deformado (fenómeno que se ha observado a la edad de 36 meses).

\section{c) Sistemas: cemento 1/escoria-disolución 4 $\left(128,80 \mathrm{~g} / \mathrm{l}\right.$ de $\left.\mathrm{MgSO}_{4} .7 \mathrm{H}_{2} \mathrm{O}\right)$}

Las series de probetas de mortero (1:3) de $1 \times 1 \times 6 \mathrm{~cm}$ hechas con cemento 1 y con las diversas mezclas cemento 1 /escoria reseñadas en 2.2.1, sumergidas en la disolución de $\mathrm{MgSO}_{4} .7 \mathrm{H}_{2} \mathrm{O}-128,80 \mathrm{~g} / \mathrm{l}<>50,200 \mathrm{~g} / \mathrm{l}$ de $\mathrm{SO}_{4}$ (II), $\langle>12,720 \mathrm{~g} / \mathrm{l}$ de $\mathrm{Mg}$ (II)- durante $56,90,180$ y 360 días, experimentan una pérdida superficial de la pasta de cemento hidratado, que se inicia en las primeras edades en las probetas que tienen mayores contenidos de escoria (fotogradía 4); además, aparece un precipitado superficial. Esta pérdida de masa, acentuada con el contenido de escoria en la mezcla utilizada para fabricar las probetas de mortero, hace que las probetas experimenten una disminución de las resistencias mecánicas, a flexotracción, del $57 \%$ y del $42 \%$ a los 180 días - según se trate de las series correspondientes a las mezclas que tienen 60 y $70 \%$ (en peso) de escoria, respectivamentey que a los 365 dias se desintegren.

Las probetas elaboradas con el cemento 1 experimentan un descenso en las resistencias mecánicas del $21 \%$ a 365 días, edad en la que dichas probetas muestran el ataque iniciado por las aristas (fotografía 1). El descenso de dichas resistencias correspondientes a las series de probetas hechas con las mezclas que tienen 15 y $35 \%$ (en peso) de escoria, a la edad de 365 días, es del 31 y del 57 $\%$, respectivamente.

\section{d) Sistemas: cemento 1/escoria-disolución 5 $\left(515,20 \mathrm{~g} / \mathrm{l}\right.$ de $\left.\mathrm{MgSO}_{4} .7 \mathrm{H}_{2} \mathrm{O}\right)$}

Del mismo modo que en los sistemas del apartado anterior, las series de probetas sumergidas en la disolución que tiene $515,20 \mathrm{~g} / \mathrm{l}$ de $\mathrm{MgSO}_{4} .7 \mathrm{H}_{2} \mathrm{O}<>200,80 \mathrm{~g} / \mathrm{l}$ de $\mathrm{SO}_{4}$ (II), $<>$ $<>50,880 \mathrm{~g} / \mathrm{l}$ de $\mathrm{Mg}$ (II), experimentan una pérdida de la pasta de cemento hidratado más intensa que en dichos sistemas, habiéndose puesto de manifiesto en la primera edad (56 dias), como se puede apreciar en la fotografía 5.

La pérdida de pasta de cemento es más intensa cuanto mayor es la cantidad de escoria en la mezcla utilizada para fabricar las probetas de mortero. Las probetas llegan a desintegrarse, a edades más tempranas cuanto mayor es la cantidad de escoria, apareciendo una masa que presenta dos zonas, de color claro y oscuro respectivamente, perfectamente diferenciadas, como se puede apreciar en la fotografía 5. Los fenómenos mencionados, como es. lógico, tienen su influencia en los valores de las resistencias mecánicas.

Este ataque continua, produciéndose la desintegración de dichas probetas como puede observarse en la fotografía 6 (tomada 3 años después).

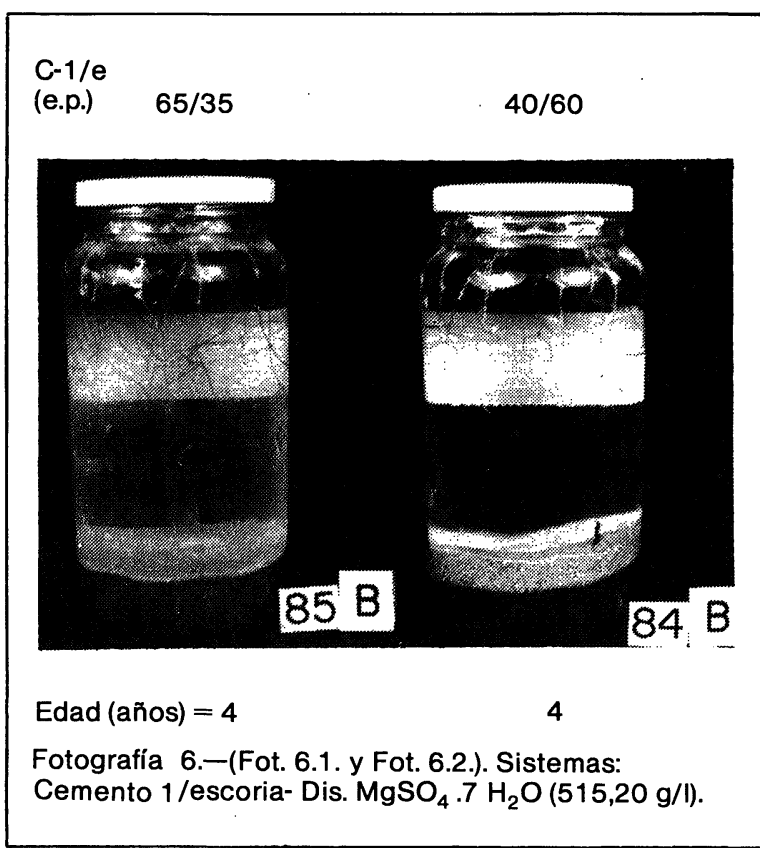

3.1.2.4. Sistemas: cemento 1/escoria-disoluciones saturadas de $\mathrm{CaSO}_{4} .2 \mathrm{H}_{2} \mathrm{O}+$ $+\mathrm{MgSO}_{4} .7 \mathrm{H}_{2} \mathrm{O}(3,22$ y $32,20 \mathrm{~g} / \mathrm{l})$

En las figuras 9 y 10 se han representado los valores de las resistencias mecánicas, a flexotracción, $\left(\mathrm{Kp} / \mathrm{cm}^{2}\right)$ de las series de probetas de mortero (1:3) de $1 \times 1 \times 6 \mathrm{~cm}$ (valores medios de 12 probetas, por serie y por edad), hechas con el cemento 1 y con las mezclas cemento 1/escoria mencionadas en 2.2.1 - sumergidas unas series en una disolución saturada de yeso a la que se le han adicionado $3,22 \mathrm{~g} / \mathrm{l}$ de $\mathrm{MgSO}_{4} .7 \mathrm{H}_{2} \mathrm{O}$ (disolución 6) y otras 
series análogas en una disolución saturada de yeso con $32,20 \mathrm{~g} / \mathrm{l}$ de $\mathrm{MgSO}_{4} .7 \mathrm{H}_{2} \mathrm{O}$ (disolución 7)- en función de los tiempos de conservación-ataque (hasta 3 años).

\section{a) Sistemas: cemento 1/escoria-disolución 6}

En estos sistemas, como en los que se describen en los puntos 3.1.2.1, 3.1.2.2 y 3.1.2.3, apartado a, la adición de escoria favorece el comportamiento mecánico-resistente del cemento 1, cuando las probetas de mortero-elaboradas con dicho cemento y con sus mezclas con escoria- se someten durante los períodos de tiempo señalados en 2.2.1 a la acción de la disolución 6 que tiene una concentración de $\mathrm{SO}_{4}$ (II) $=2,273 \mathrm{~g} / \mathrm{l}$, de $\mathrm{Ca}$ (II) $=$ $=0,420 \mathrm{~g} / \mathrm{l}$ y de $\mathrm{Mg}$ (II) =0,318 $\mathrm{g} / \mathrm{l}$, como se puede apreciar en la figura 9.

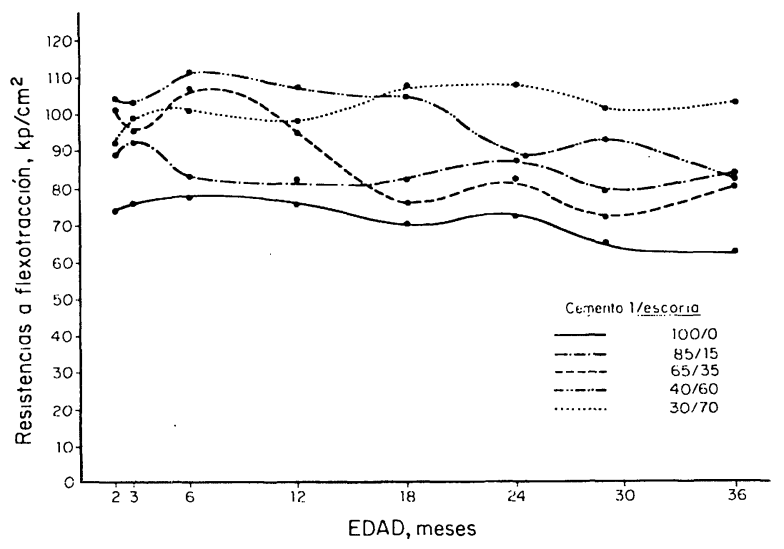

Fig. 9.-Sistemas: C-1/escoria - Dis. saturada de yeso + $+\mathrm{MgSO}_{4} .7 \mathrm{H}_{2} \mathrm{O}(3,22 \mathrm{~g} / \mathrm{l})$. Evolución de las resistencias mecánicas, a flexotracción.

Las resistencias mecánicas, a flexotracción, más elevadas hasta 360 días corresponden a las series de probetas hechas con la mezcla cemento 1 /escoria $=40 / 60$ (en peso) y desde esta edad hasta 36 meses a las de la mezcla que tiene $70 \%$ (en peso) de escoria.

Teniendo en cuenta los resultados obtenidos se puede establecer, desde un punto de vista mecánico-resistente, a flexotracción, la siguiente escala:

$$
\begin{gathered}
\text { cemento } 1 / \text { escoria }=40 / 60>30 / 70> \\
>85 / 15>65 / 35>100 / 0
\end{gathered}
$$

\section{b) Sistemas: cemento 1/escoria-disolución 7}

El comportamiento mecánico-resistente de estos sistemas es muy parecido al del sistema cemento 1/escoria-disolución de $\mathrm{MgSO}_{4}$.
$7 \mathrm{H}_{2} \mathrm{O}(32,20 \mathrm{~g} / \mathrm{l})$, como se puede apreciar en las figuras 8 y 10. Así, tiene lugar una disminución de las resistencias mecánicas conforme aumente el tiempo de ataque y las probetas hechas con la mezcla que tiene el $15 \%$ (en peso) de escoria aparecen agrietadas, a la edad de 18 meses (fotografias 7 y 3 ), del mismo modo en ambos sistemas. Las resistencias menores (hasta 3 años) correponden a las series fabricadas con las mezclas cemento $1 /$ escoria $=100 / 0$ y $65 / 35$, en peso y las mejores a las mezclas que tienen el mayor contenido de escoria $(70 \%)$.

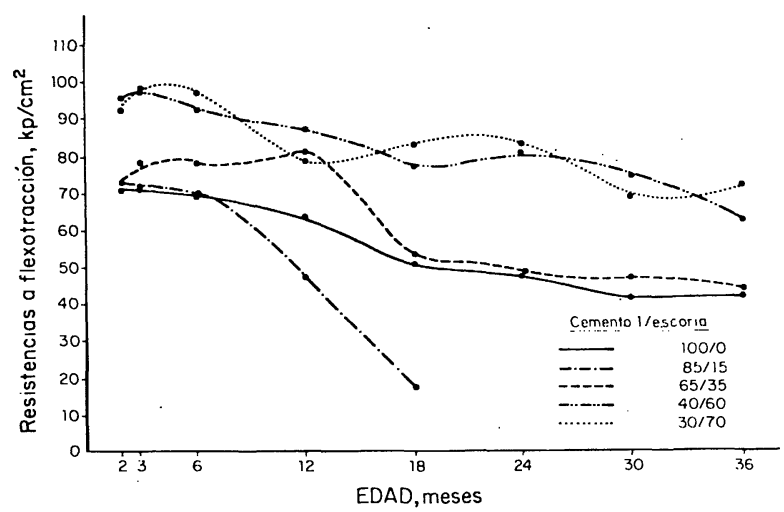

Fig. 10.-Sistemas: C-1/escoria - Dis. saturada de yeso + $+\mathrm{MgSO}_{4} .7 \mathrm{H}_{2} \mathrm{O}(32,20 \mathrm{~g} / \mathrm{l})$. Evolución de las resistencias mecánicas, a flexotracción.

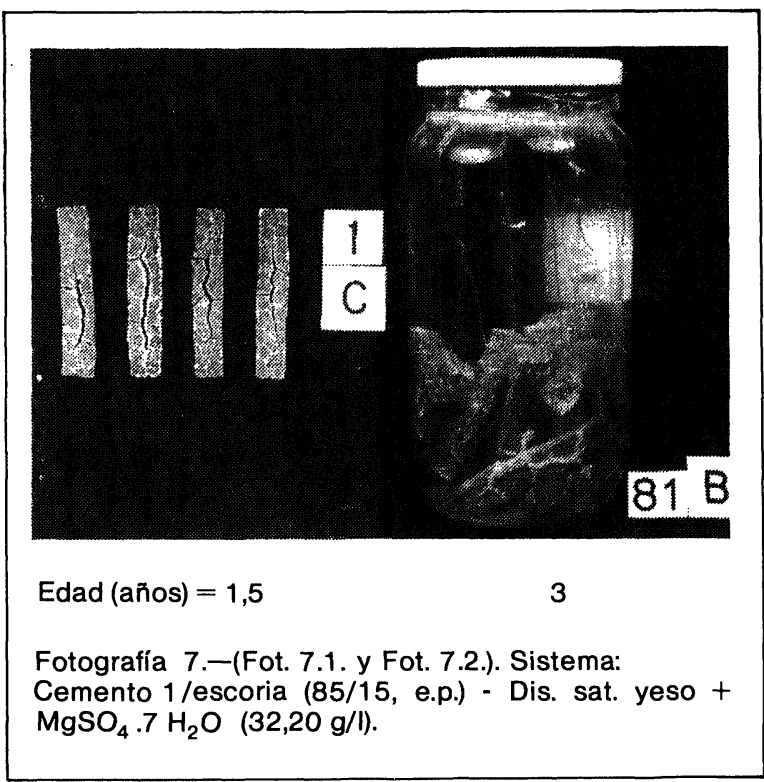

3.1.3. Sistemas: cemento 1/C.V. (EN-1)-agua potable filtrada y disoluciones agresivas

\subsubsection{Sistemas: cemento 1/C.V.(EN-1)-agua potable filtrada}

En la figura 11 se han representado los valo- 
res de las resistencias mecánicas, a flexotracción, $\left(\mathrm{Kp} / \mathrm{cm}^{2}\right)$ de las probetas de mortero (1:3) de $1 \times 1 \times 6 \mathrm{~cm}$ (valores medios de 12 probetas, por serie y por edad) -hechas con el cemento 1 y con las mezclas cemento 1/C.N. (EN-1) mencionadas en 2.2.1- en función del tiempo de conservación (hasta 3 años) en agua potable filtrada.

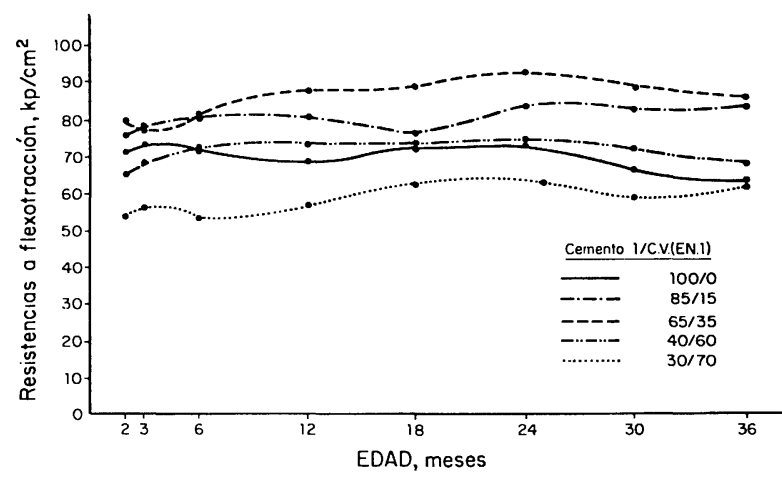

Fig. 11.-Sistemas: C-1/C.V. (EN-1)-agua potable filtrada. Evolución de las resistencias mecánicas, a flexotracción.

Las resistencias mecánicas, a flexotracción, de las series de probetas, sumergidas en agua potable filtrada durante los periodos de tiempo reseñados en 2.2.1, hechas con las mezclas que tienen $15-35$ y $60 \%$, en peso, de la ceniza volante estudiada son superiores que las correspondientes a las series análogas elaboradas con el cemento 1 y éstas, a su vez, mayores que las de las probetas fabricadas con la mezcla que tiene $70 \%$, en peso, de la ceniza volante.

De acuerdo con los valores obtenidos se puede establecer, según el comportamiento mecánico-resistente, a flexotracción, la siguiente clasificación:

$$
\begin{gathered}
\text { cemento } 1 / \text { C.V. }(E N-1)=65 / 35>85 / 15> \\
>40 / 60>100 / 0>30 / 70
\end{gathered}
$$

de tal modo que el incremento - de dichas resistencias- experimentado por las series hechas con el $35 \%$, en peso, de ceniza volante, con relación a las fabricadas con cemento 1 , se encuentra comprendido entre el $14 \%$ (56 dias) y $31 \%$ (a partir de 540 días).

\subsubsection{Sistemas: cemento 1/C.V. (EN-1)-di- solución saturada de yeso}

En la figura 12 se han representado los valores de las resistencias mecánicas, a flexotracción, $\left(\mathrm{Kp} / \mathrm{cm}^{2}\right)$ de las probetas de mortero $(1: 3)$ de $1 \times 1 \times 6 \mathrm{~cm}$ (valores medios de 12 probe- tas, por serie y por edad) - hechas con el cemento 1 y con sus mezclas con la ceniza volante $E N-1$, reseñadas en 2.2.1- en función del tiempo de conservación-ataque (hasta 3 años) en una disolución saturada de yeso.

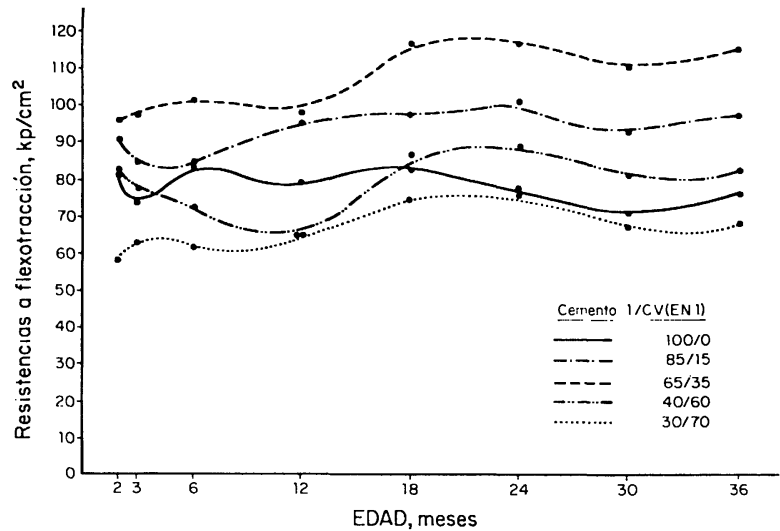

Fig. 12.-Sistemas: C-1/C.V. (EN-1) - Dis. saturada de yeso. Evolución de las resistencias mecánicas, a flexotracción.

Las resistencias mecánicas a flexotracción de las series de probetas hechas con las mezclas que tienen 35 y $15 \%$, en peso, de la ceniza volante, para todas las edades, y $40 \%$ a partir de 18 meses, son superiores que las correspondientes a las series análogas elaboradas con el cemento 1 , cuando se sumergen durante los períodos de tiempo mencionados en 2.2.1 en una disolución saturada de yeso. Las series hechas con la mezcla que tiene 70 $\%$, en peso, de la ceniza volante presentan los valores menores.

De acuerdo con los valores obtenidos se puede establecer la siguiente escala, según el comportamiento mecánico-resistente a flexotacción:

$$
\begin{gathered}
\text { cemento } 1 / \mathrm{C} . \mathrm{V} .(\mathrm{EN}-1)=65 / 35>85 / 15> \\
>40 / 60 \gtrless 100 / 0>30 / 70
\end{gathered}
$$

de tal modo que el incremento experimentado por las series de probetas hechas con la mezcla que tiene $35 \%$, en peso, de ceniza volante, con relación a las elaboradas con el cemento 1 , es del $19 \%$ para la edad de 56 días y superior del $50 \%$ para las tres edades finales $(24,30$ y 36 meses).

3.1.3.3. Sistemas: cemento 1/C.V. (EN-1)-disoluciones de sulfato de magnesio

En las figuras 13 y 14 se han representado las resistencias mecánicas, a flexotracción, 
$\left(\mathrm{Kp} / \mathrm{cm}^{2}\right)$ de las probetas de mortero $(1: 3)$ de $1 \times 1 \times 6 \mathrm{~cm}$ (valores medios de 12 probetas, por serie y por edad) - hechas con el cemento 1 y con las mezclas con la ceniza volante EN-1 señaladas en 2.2.1, sumergidas en la disolución 2 (tiene 3,22 $\mathrm{g} / \mathrm{l}$ de $\mathrm{MgSO}_{4} .7 \mathrm{H}_{2} \mathrm{O}$ ) y en la disolución 3 (tiene $32,20 \mathrm{~g} / \mathrm{l}$ de $\mathrm{MgSO}_{4} .7 \mathrm{H}_{2} \mathrm{O}$ ), respectivamente-en función del tiempo de conservación-ataque (hasta 3 años).

a) Sistemas: cemento 1/C.V. (EN-1)-disolución $2\left(3,22 \mathrm{~g} / \mathrm{l}\right.$ de $\left.\mathrm{MgSO}_{4} .7 \mathrm{H}_{2} \mathrm{O}\right)$

En la figura 13 se puede observar que la adición de la ceniza volante en determinadas cantidades (15 y $35 \%$, especialmente) favorece el comportamiento mecánico-resistente, a flexotracción, de las probetas de mortero hechas con el cemento 1 , cuando se someten a la acción de una disolución de sulfato de magnesio $\left[3,22 \mathrm{~g} / \mathrm{l}\right.$ de $\mathrm{MgSO}_{4} .7 \mathrm{H}_{2} \mathrm{O} \quad<>$ <> 1,1263 g/l de $\mathrm{SO}_{4}$ (II), <> 0,318 g/l de $\mathrm{Mg}$ (II)] durante los períodos de tiempo mencionados en 2.2.1.

De acuerdo con los valores obtenidos se puede establecer, desde un punto de vista de su comportamiento mecánico-resistente, a flexotracción, la siguiente escala:

$$
\begin{gathered}
\text { cemento } 1 / \text { C.V. }(E N-1)=65 / 35>85 / 15> \\
>40 / 60 \simeq 100 / 0>30 / 70
\end{gathered}
$$

Los valores más altos, con relación a las probetas hechas con cemento 1 , corresponden a las de las series elaboradas con la mezcla que tiene $35 \%$ de ceniza volante (las resistencias han experimentado un incremento comprendido entre el $25 \%$, a 56 días, y el $37 \%$, a los 18 , 24 y 36 meses).

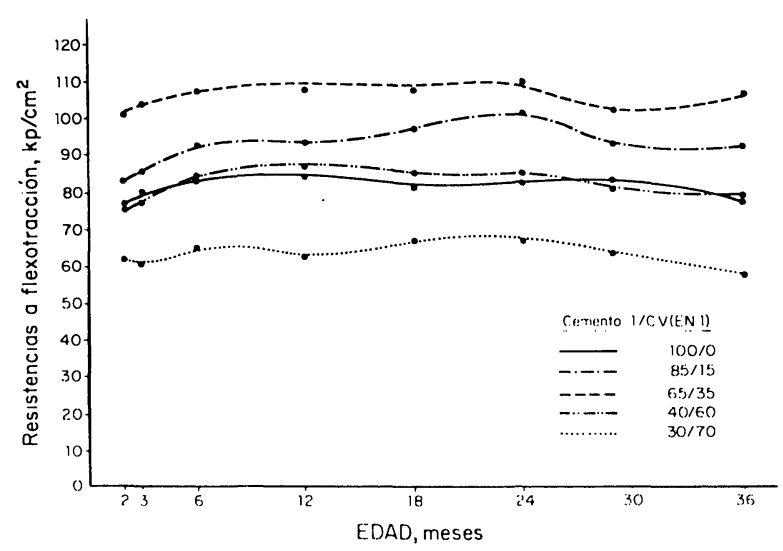

Fig. 13.-Sistemas: C-1/C.V. $(\mathrm{EN}-1)$ - Dis. $\mathrm{Mg} \mathrm{SO}_{4} .7 \mathrm{H}_{2} \mathrm{O}$ $(3,22 \mathrm{~g} / \mathrm{l})$. Evolución de las resistencias mecánicas, a flexotracción. b) Sistema: cemento 1/C.V. (EN-1)-disolución $3\left(32,20 \mathrm{~g} / \mathrm{l} \mathrm{de} \mathrm{MgSO}_{4} .7 \mathrm{H}_{2} \mathrm{O}\right)$

En la figura 14 se aprecia que las resistencias mecánicas, a flexotracción, de las series de probetas hechas con cemento 1 y con la mezcla que tiene el $15 \%$, en peso, de ceniza volante experimentan un descenso (del $40 \%$ ) desde la primera edad (56 dias) hasta la de 30 meses, mientras que las resistencias correspondientes a las mezclas cemento 1/C.V. (EN1) $=65 / 35,30 / 70$ y $40 / 60$ pasan de $87-76$ y $83 \mathrm{Kp} / \mathrm{cm}^{2}$ a 56 días a $80-83$ y $76 \mathrm{Kp} / \mathrm{cm}^{2}$ a los 36 meses.

De acuerdo con los valores obtenidos se puede establecer, desde un punto de vista de su comportamiento mecánico-resistente, la siguiente escala:

$$
\begin{gathered}
\text { cemento } 1 / \text { C.V. }(E N-1)=65 / 35>30 / 70> \\
>40 / 60>100 / 0>85 / 15
\end{gathered}
$$

Las probetas hechas con la mezcla que tiene el $15 \%$, en peso, de cenizas volantes aparecen agrietadas, iniciándose el ataque por las aristas a los 2,5 años. Asimsmo, las series de probetas elaboradas con el cemento 1 se han deformado, como se señaló en los apartados 3 y a) de los puntos 3.1.1 y 3.1.2.3, respectivamente.

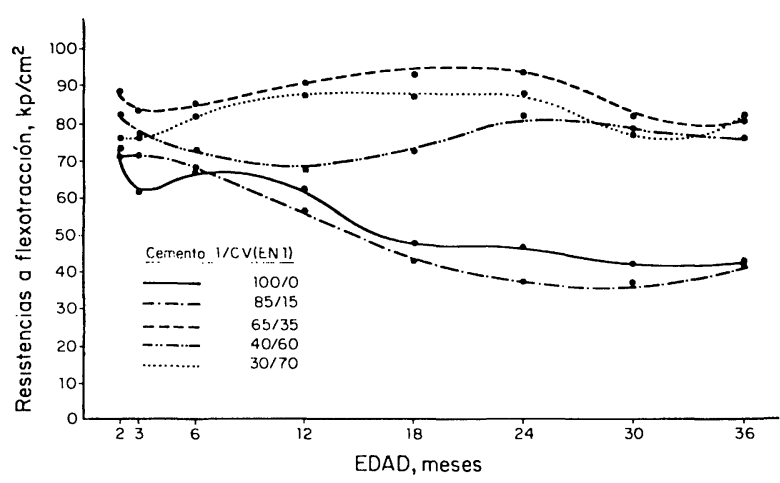

Fig. 14.-Sistemas: C-1/C.V. (EN-1) - Dis. $\mathrm{MgSO}_{4} .7 \mathrm{H}_{2} \mathrm{O}$ $(32,20 \mathrm{~g} / \mathrm{l})$. Evolución de las resistencias mecánicas, a flexotracción.

c) Sistemas: cemento 1/C.V. (EN-1)-disolución $4\left(128,80 \mathrm{~g} / \mathrm{l}\right.$ de $\left.\mathrm{MgSO}_{4} .7 \mathrm{H}_{2} \mathrm{O}\right)$

Las series de probetas de mortero (1:3) de $1 \times 1 \times 6 \mathrm{~cm}$ hechas con cemento 1 y con las diversas mezclas cemento 1/C.V. (EN-1) reseñadas en 2.2.1, sumergidas en la disolución de $\mathrm{MgSO}_{4} .7 \mathrm{H}_{2} \mathrm{O}-128,80 \mathrm{~g} / \mathrm{l}<>50,200 \mathrm{~g} / \mathrm{l}$ de $\mathrm{SO}_{4}(\mathrm{II}),<>12,720 \mathrm{~g} / \mathrm{l}$ de $\mathrm{Mg}$ (II)- durante $56,90,180$ y 360 días, experimentan una pérdida superficial de la pasta de cemento hidra- 


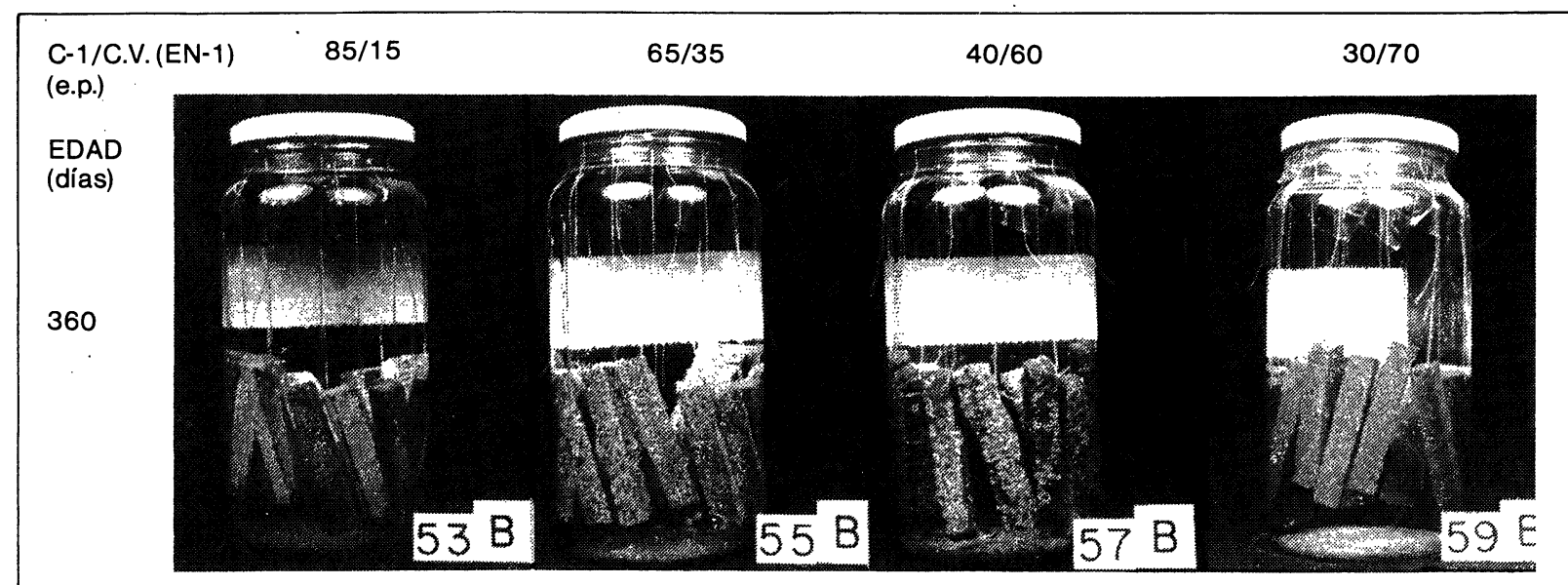

Fotografía 8.-(Fot. 8.1. a Fot. 8.4.). Sistemas: Cemento 1/C.V. (EN-1) - Dis. $\mathrm{MgSO}_{4} .7 \mathrm{H}_{2} \mathrm{O}(128,80 \mathrm{~g} / \mathrm{l})$.

tado, que se inicia en las primeras edades en las probetas que tien ' $n$ mayores contenidos de ceniza volante (fotografía 8). Esta pérdida de pasta, acentuada con el contenido de ceniza volante en la mezcla utilizada para fabricar las probetas de mortero (de un modo especial la que tiene el $60 \%$ en peso), hace que las probetas experimenten una disminución de las resistencias mecánicas, a flexotracción, del 63 y del $40 \%$ a los 90 días, según se trate de las series correspondientes a las mezclas que tienen 60 y $70 \%$, en peso, de cenizas y que posteriormente se desintegren.

d) Sistemas: cemento 1/C.V. $(\mathrm{EN}-1)$-disolución $5\left(515,20 \mathrm{~g} / \mathrm{l}\right.$ de $\left.\mathrm{MgSO}_{4} .7 \mathrm{H}_{2} \mathrm{O}\right)$

Del mismo modo que en los sistemas del apartado anterior, las series de probetas sumergidas en la disolución que tiene $515,20 \mathrm{~g} / \mathrm{l}$ de $\mathrm{MgSO}_{4} \cdot 7 \cdot \mathrm{H}_{2} \mathrm{O}<>200,80 \mathrm{~g} / \mathrm{l}$ de $\mathrm{SO}_{4}$ (II), <> $<50,880 \mathrm{~g} / \mathrm{l}$ de $\mathrm{Mg}$ (II), experimentan una pérdida de la pasta de cemento hidratado más intensa que en dichos sistemas, habiéndose puesto de manifiesto en la primera edad (56 días), como se puede apreciar en la fotografía 9.

La pérdida de pasta es más intensa cuanto mayor es la cantidad de ceniza volante en la mezcla utilizada para fabricar las probetas de mortero; como consecuencia de ello, dichas probetas se desintegran a edades más tempranas, como ha sucedido con las correspondientes a las mezclas que tienen 60 y $70 \%$, en peso, de la ceniza volante EN-1 (fotografía 9), que carecian de resistencias a los 56 dias de estar sometidas a la acción de esta disolución.
3.1.3.4. Sistemas: cemento 1/C.V. (EN-1)-disoluciones saturadas de $\mathrm{CaSO}_{4}$. $.2 \mathrm{H}_{2} \mathrm{O}+\mathrm{MgSO}_{4} .7 \mathrm{H}_{2} \mathrm{O}(3,22 \mathrm{y}$ $32,20 \mathrm{~g} / \mathrm{l})$

En las figuras 15 y 16 se han representado los valores de las resistencias mecánicas, a flexotracción, $\left(\mathrm{Kp} / \mathrm{cm}^{2}\right)$ de las series de probetas de mortero (1:3) de $1 \times 1 \times 6 \mathrm{~cm}$ (valores medios de 12 probetas, por serie y por edad), hechas con el cemento 1 y con las mezclas cemento 1/ceniza volante EN-1 mencionadas en 2.2.1 - sumergidas unas series en una disolución saturada de yeso a la que se le han adicionado $3,22 \mathrm{~g} / \mathrm{l}$ de $\mathrm{MgSO}_{4} .7 \mathrm{H}_{2} \mathrm{O}$ (disolución 6) y otras series análogas en una disolución saturada de yeso con $32,20 \mathrm{~g} / \mathrm{l}$ de $\mathrm{MgSO}_{4} .7 \mathrm{H}_{2} \mathrm{O}$ (disolución 7 )- en función de los tiempos de conservación-ataque (hasta 3 años).

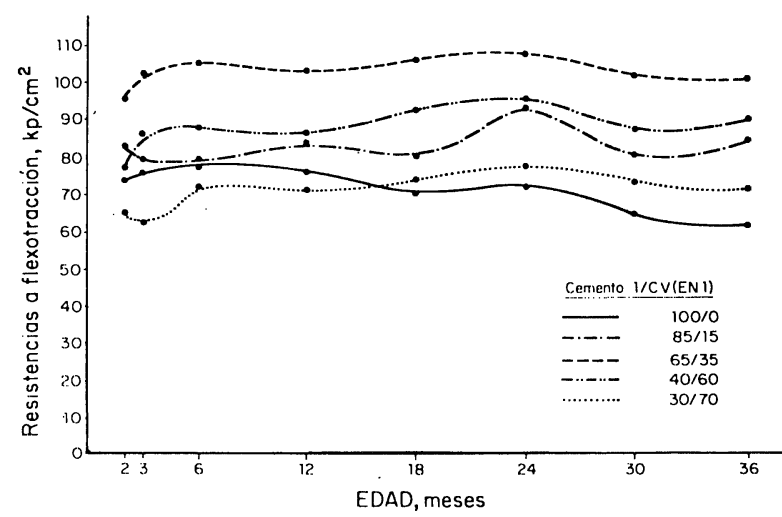

Fig. 15.-C-1/C.V. (EN-1) - Dis. saturada de yeso $+\mathrm{MgSO}_{4}$. $.7 \mathrm{H}_{2} \mathrm{O}(3,22 \mathrm{~g} / \mathrm{l})$. Evolución de las resistencias mecánicas, a flexotracción. 


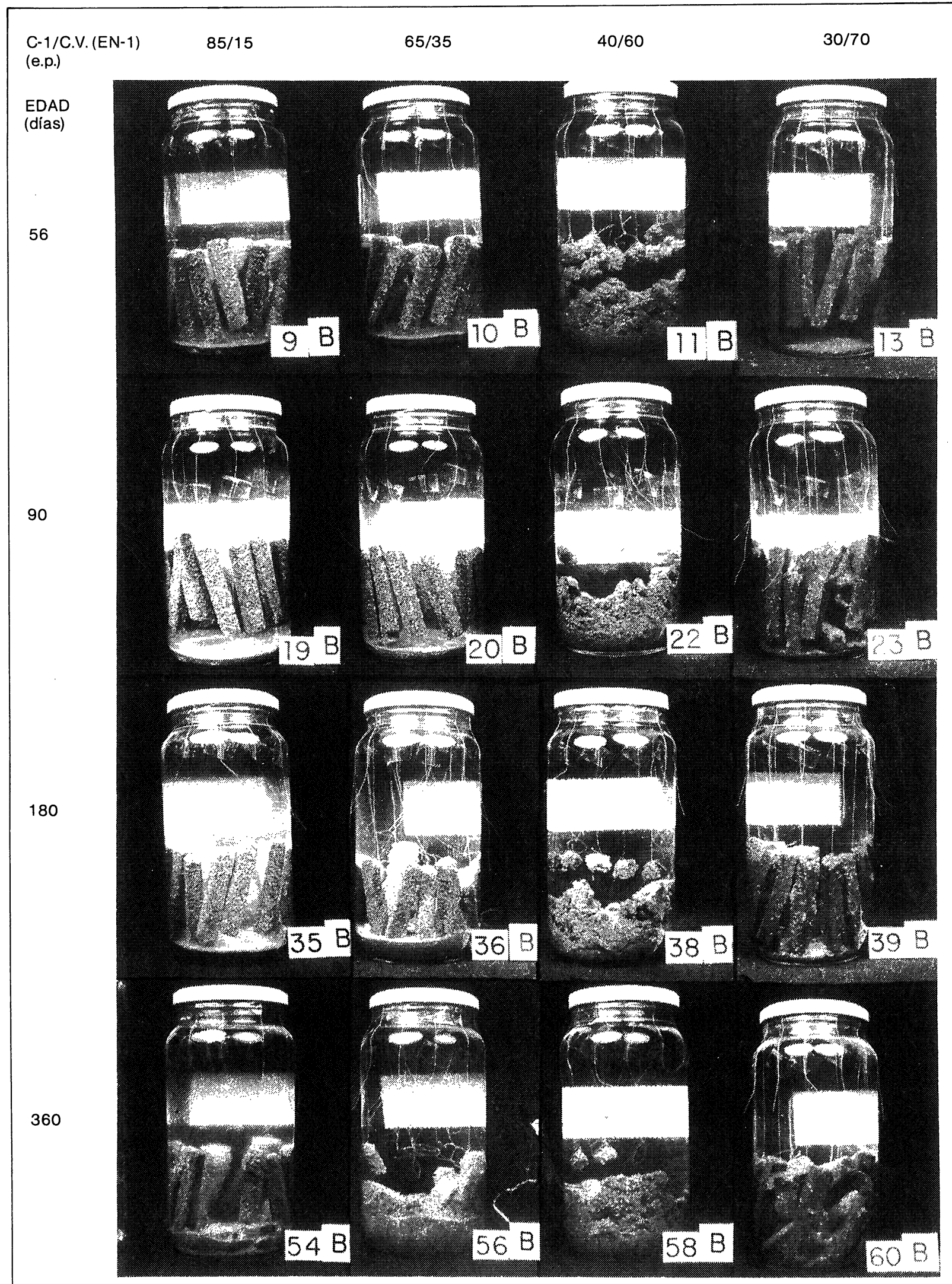

Fotografia 9.-Fot. 9.1. a 9.16. Sistemas: Cemento 1/C.V. (EN-1) - Dis. $\mathrm{MgSO}_{4} .7 \mathrm{H}_{2} \mathrm{O}(515,20 \mathrm{~g} / \mathrm{l})$. 
a) Sistemas: cemento 1/C.V. (EN-1)-disolución 6

En estos sistemas, la adición del 15, 35 y 60 $\%$, en peso, a todas las edades, y del $70 \%$, en las cuatro primeras edades de la ceniza volante EN-1, favorece el comportamiento mecánico-resistente del cemento 1, cuando las probetas de mortero elaboradas con este cemento y con sus mezclas con la mencionada ceniza volante se someten -durante los períodos de tiempo mencionados en 2.2.1- a la acción de la disolución 6 , como se puede apreciar en la figura 15.

Teniendo en cuenta los resultados obtenidos se puede establecer, desde un punto de vista mecánico-resistente a flexotracción, la siguiente escala:

$$
\begin{gathered}
\text { cemento } 1 / \mathrm{C} . \mathrm{V} .(\mathrm{EN}-1)=65 / 35>40 / 60> \\
>85 / 15>100 / 0 \gtrless 30 / 70
\end{gathered}
$$

\section{b) Sistemas: cemento 1/C.V. (EN-1)-disolu- ción 7}

El comportamiento mecánico-resistente de estos sistemas es muy parecido al de los sistemas cemento 1/C.V. (EN-1)-disolución 3 $\left(32,20 \mathrm{~g} / \mathrm{l}\right.$ de $\left.\mathrm{MgSO}_{4} .7 \mathrm{H}_{2} \mathrm{O}\right)$ como se puede apreciar en las figuras 14 y 16 . Del mismo modo, se produce un descenso de las resistencias mecánicas, a flexotracción, de las series de probetas de mortero hechas con cemento 1 y con la mezcla que tiene el $15 \%$, en peso, de la ceniza volante, que llega a ser del $40 \%$ considerando la primera edad (56 días) y 30 meses.

Por el contrario, las resistencias correspondientes a las probetas elaboradas con las mezclas cemento $1 /$ C.V. $(E N-1)=65 / 35,30 / 70$ y $40 / 60$, en peso, pasan de $75-92 \mathrm{Kp} / \mathrm{cm}^{2}$, a

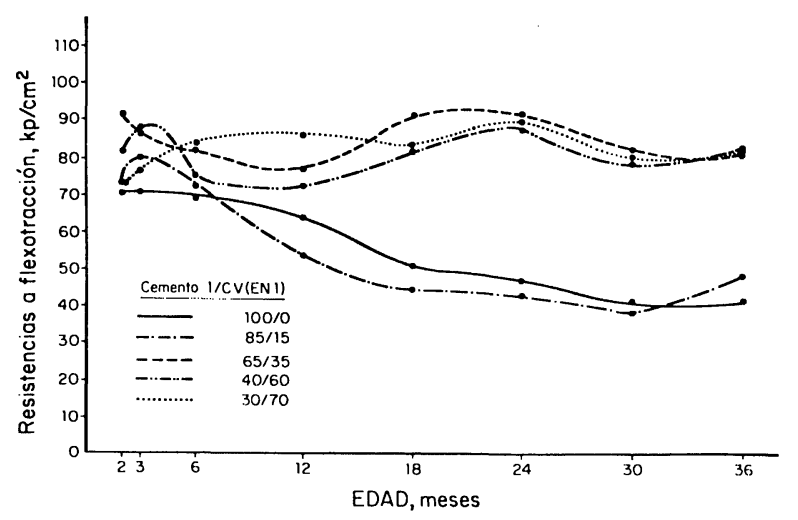

Fig. 16.-Sistemas: C-1/C.V. (EN-1) - Dis. saturada de yeso $+\mathrm{MgSO}_{4} .7 \mathrm{H}_{2} \mathrm{O}(32,20 \mathrm{~g} / \mathrm{l})$. Evolución de las resistencias mecánicas, a flexotracción.
56 días, a $81-83 \mathrm{Kp} / \mathrm{cm}^{2}$, a los 36 meses. De aquí, que se puede establecer la siguiente graduación:

$$
\begin{gathered}
\text { cemento } 1 / \text { C.V. }(\mathrm{EN}-1)=65 / 35 \gtrless 30 / 70> \\
>40 / 60>100 / 0>85 / 15
\end{gathered}
$$

\section{ESTUDIO DE LA CONCENTRACION IÓNICA}

Las reacciones químicas entre los iones presentes en las disoluciones agresivas y los compuestos hidratados de la pasta de cemento, así como con los compuestos de la escoria y de la ceniza volante, por una parte, y con los iones aportados al medio por la disolución de ciertos compuestos del cemento hidratado -fundamentalmente, del $\mathrm{Ca}(\mathrm{OH})_{2}$ - conducen a la formación de nuevos compuestos y a la eliminación de otros en el seno de las probetas de mortero y en el medio, en donde se ha formado una nueva fase sólida, modificando la composición iónica de dicho medio y afectando al comportamiento mecánico-resistente de las probetas. El estudio correspondiente, que actualmente se está efectuando, será objeto de otras publicaciones.

No obstante, a partir de las determinaciones analíticas realizadas se deduce que el contenido de iones $\mathrm{Ca}$ (II) en las disoluciones a base de sulfato de magnesio en donde han estado sumergidas las diversas series de probetas de mortero se incrementa, mientras que el de los iones $\mathrm{Mg}$ (II) y $\mathrm{SO}_{4}$ (II) disminuye.

El aumento del contenido de iones $\mathrm{Ca}$ (II) en la disolución que tiene $\mathrm{SO}_{4}$ (II) $=1,263 \mathrm{~g} / \mathrm{l}$ y $\mathrm{Mg}$ (II) $=0,318 \mathrm{~g} / \mathrm{l}$ es tanto menor cuanto menos clínker existe en la mezcla utilizada para fabricar las diversas series de probetas de mortero; en las disoluciones restantes se mantiene, prácticamente, constante.

Los iones $\mathrm{Mg}$ (II) de la disolución que tiene $1,263 \mathrm{~g} / \mathrm{l}$ de $\mathrm{SO}_{4}$ (II) y 0,318 $\mathrm{g} / \mathrm{l}$ de $\mathrm{Mg}$ (II) han desaparecido y disminuyen en los casos restantes; en las disoluciones con 12,630 y 3,180 $\mathrm{g} / \mathrm{I}$ de $\mathrm{SO}_{4}$ (II) y de $\mathrm{Mg}$ (II) $\mathrm{o}$ con 13,640 $-3,180$ y $0,420 \mathrm{~g} / \mathrm{l}$ de iones $\mathrm{SO}_{4}$ (II) - Mg (II) y Ca (II), esta disminución es mayor cuanto más ceniza volante hay en la mezcla utilizada para fabricar las probetas $y$, al contrario, cuanto menos escoria existe. Sin embargo, en las disoluciones cuyos contenidos de $\mathrm{Mg}$ (II) son 12,720 y $50,820 \mathrm{~g} / \mathrm{l}$ y los de $\mathrm{SO}_{4}$ (II) 50,200 y $200,800 \mathrm{~g} / \mathrm{l}$, dicha disminución ( 20 ó $30 \%$ para las probetas hechas con cemento 1/escoria o cemento 1/ceniza volante $E N-1$ para la primera disolución y mayor del $20 \%$ para la segunda) es, prácticamente, constante. 
El contenido de iones $\mathrm{SO}_{4}$ (II), que también disminuye en todos los casos, es función de la cantidad de clínker y del tiempo de conservación-ataque; esta disminución (25-30 \%) es mayor cuanto más clínker existe en la mezcla en el caso de las disoluciones que tienen hasta $13,640 \mathrm{~g} / \mathrm{l}$ de dichos iones y permanece, prácticamente, constante en las restantes disoluciones.

Las disoluciones que tienen $0,318 \mathrm{~g} / \mathrm{l}$ de $\mathrm{Mg}$ (II) y $1,263 \mathrm{~g} / \mathrm{l}$ de $\mathrm{SO}_{4}$ (II), al encontrarse en contacto tanto con las probetas como con el medio con $\mathrm{pH}>10,5$ se produce la precipitación del $\mathrm{Mg}(\mathrm{OH})_{2}$, que actúa colmatando los poros y formando una capa protectora que beneficia el comportamiento mecánico-resistente; proceso que se ha puesto de manifiesto en otros trabajos. Sin embargo, las disoluciones que tienen contenidos de $\mathrm{SO}_{4} \geq 50,200 \mathrm{~g} / \mathrm{l}$ $y$ de $\mathrm{Mg} \geq 12,720 \mathrm{~g} / \mathrm{l}$ conducen, rápidamente, $\mathrm{a}$ fenómenos de corrosión en las caras externas de las probetas desde las primeras edades; se produce un descenso del $\mathrm{pH}$ en las disoluciones y se forman $\mathrm{CaSO}_{4} .2 \mathrm{H}_{2} \mathrm{O}$, en gran proporción (figura 17), $\mathrm{Mg}(\mathrm{OH})_{2}$ y además productos geliformes (no detectados por DRX) en la

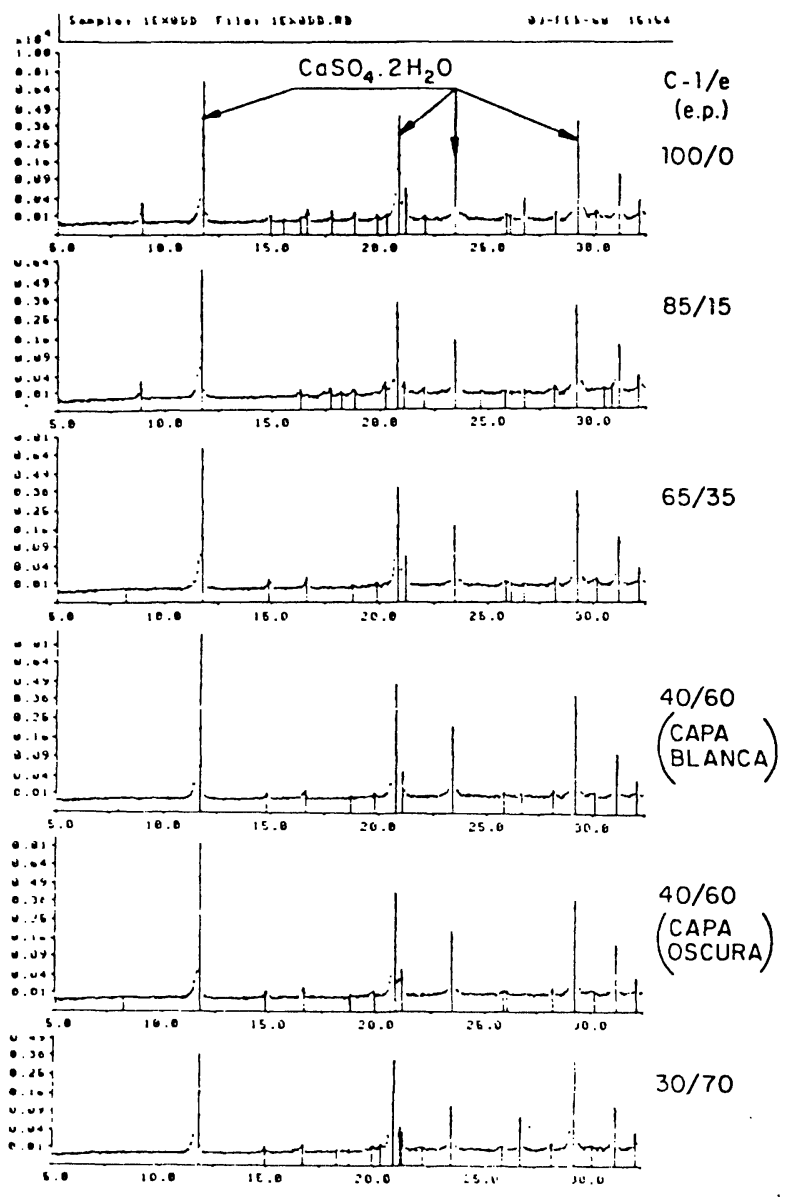

Fig. 17.-Sistemas: Cemento $1 /$ escoria - Dis. $\mathrm{MgSO}_{4}$. $7 \mathrm{H}_{2} \mathrm{O}(515,20 \mathrm{~g} / \mathrm{l})$. DRX. pasta de cemento hidratada-atacada y en la nueva fase sólida como - asímismo- ha probado Riedel (10).

La pequeña capacidad resistente de las probetas hechas con cemento 1/escoria ( $y$ con otros cementos que también se han estudiado y de cuyos resultados se dará cuenta en otros trabajos) y, sobre todo, con cantidades elevadas de escoria ( $\geq 60 \%$ ) se atribuye a la menor cantidad de portlandita puesta en juego por lo que no se forman los productos correspondientes (cristalinos y geliformes) mencionados, ni la "capa protectora" en la superficie de las probetas.

En el caso de las mezclas cemento 1/ceniza volante $\mathrm{EN}-1$ (por sus características) el $\mathrm{Ca}(\mathrm{OH})_{2}$ formado reacciona más lentamente con la ceniza volante que con la escoria y, por consiguiente, para determinadas concentraciones inferiores a éstas y superiores a las prime$\operatorname{ras}\left[\mathrm{Mg}(\mathrm{II})=0,318 \mathrm{~g} / \mathrm{l}\right.$ y $\mathrm{SO}_{4}$ (II) $\left.=1,263 \mathrm{~g} / \mathrm{I}\right]$, los fenómenos reseñados pueden no tener lugar - hecho que se piensa comprobar-, lo que explicaría el mejor comportamiento de las probetas hechas con las mezclas que tienen 35 - 60 y $70 \%$ de la ceniza volante frente a las disoluciones con 3,180 y $12,630 \mathrm{~g} / \mathrm{l}$ de $\mathrm{Mg}$ (II) y de $\mathrm{SO}_{4}$ (II) ó $3,180-13,640$ y $0,420 \mathrm{~g} / \mathrm{I}$ de $\mathrm{Mg}$ (II) $-\mathrm{SO}_{4}$ (II) y $\mathrm{Ca}$ (II).

Los contenidos de iones $\mathrm{Ca}$ (II) y $\mathrm{SO}_{4}$ (II) de la dis. saturada de yeso en donde han estado sumergidas las diversas series de probetas de mortero disminuyen; esta disminución es función del contenido de escoria o de ceniza volante EN-1, mayor para el caso de los iones $\mathrm{Ca}$ (II) cuanto más ceniza volante hay en la mezcla utilizada para fabricar las probetas y, a la inversa, menor cuanto más escoria existe. La disminución de iones $\mathrm{SO}_{4}$ (II) es mayor cuanto más clínker hay en la mezcla mencionada. Fenómenos que están ligados al comportamiento mecánico-resistente de las probetas de mortero.

\section{TRABAJOS EN MEDIOS NATURALES}

A la vista de los resultados obtenidos - de los que, en parte, se dan cuenta en este trabajocon diversos cementos de características estructurales distintas y adiciones (una escoria y tres cenizas volantes, en una primera etapa, seleccionadas por los estudios previos realizados con 19 cenizas volantes) y con el fin de ampliarlos y conocer el comportamiento de los hormigones a escala real, cuando se someten a la acción de medios agresivos naturales, se han realizado otros trabajos previos en la laguna de Pétrola (Albacete), por sus caracteristicas - aguas con una elevada concentración de sales de magnesio-, en donde se coloca- 
ron en 1985 una serie de probetas de hormigón que se vienen examinando periódicamente (fotografía 10). De los trabajos efectuados, así como del Programa de Trabajo a desarrollar se dará cuenta en otras publicaciones.

\section{RESUMEN Y CONCLUSIONES}

\section{Primera}

En este trabajo se ha probado que la adición de escoria en las cantidades estudiadas y de la ceniza volante $E N-1$, excepto el $70 \%$ en peso, al cemento 1 favorece el comportamiento mecánico-resistente, a flexotracción, de las probetas de mortero (1:3) de $1 \times 1 \times 6 \mathrm{~cm}$ sometidas a la acción de una dis. saturada de yeso, de una disolución de sulfato de magnesio [cuyas concentraciones de $\mathrm{SO}_{4}$ (II) y de $\mathrm{Mg}$ (II) son 1,263 y $0,318 \mathrm{~g} / \mathrm{l}$, respectivamente] y de la dis. saturada de yeso más sulfato de magnesio [las concentraciones de $\mathrm{SO}_{4}$ (II), $\mathrm{Mg}$ (II) y Ca (II) son $2,273,0,318$ y $0,420 \mathrm{~g} / \mathrm{ll}$. Las adiciones óptimas, que han proporcionado las resistencias más elevadas - todas ellas superiores a las de las probetas análogas conservadas bajo agua-, han sido 60 y $70 \%$ de escoria y $35 \%$, en peso, de ceniza volante.

\section{Segunda}

Cuando las concentraciones de iones $\mathrm{SO}_{4}$ (II) y $\mathrm{Mg}$ (II) de las disoluciones son 12,630 y $3,180 \mathrm{~g} / \mathrm{l}$ y las de los iones $\mathrm{SO}_{4}$ (II), $\mathrm{Mg}$ (II) y $\mathrm{Ca}$ (II) 13,640 - 3,180 y 0,420 g/l, respectivamente, las resistencias mecánicas, a flexotracción, de las probetas hechas con cemento 1 y con sus mezclas con escoria disminuyen a lo largo del tiempo. Esta disminución es pronun-

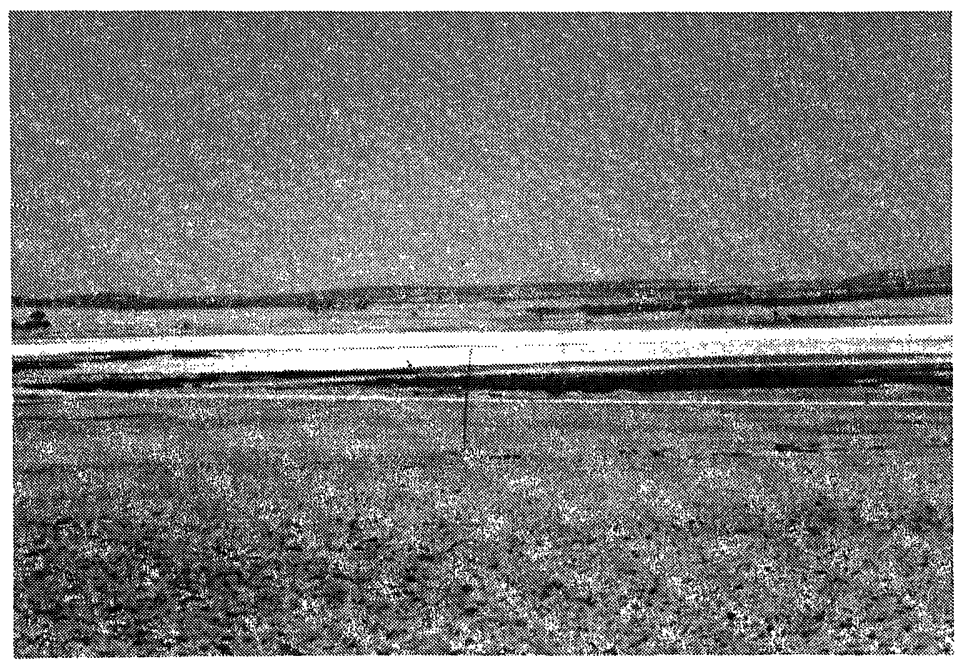

ciada en el caso de las probetas hechas con cemento y con las mezclas que tienen las menores cantidades de escoria; con el $35 \%$, en peso, de escoria dicha disminución es del mismo orden y con el $15 \%$ es más pronunciada, de tal modo que las probetas se han fisurado y deformado a los 18 meses. Por el contrario, las series de probetas fabricadas con las mezclas cemento $1 /$ ceniza volante $(E N-1)=65 / 35$ (mezcla óptima), $30 / 70$ y $40 / 60$, en peso, son resistentes frente a estas disoluciones durante el período de tiempo estudiado (3 años), no habiendo experimentado, prácticamente, disminución de las resistencias mecánicas mencionadas, con relación a las de los correspondientes testigos sumergidos en agua potable filtrada.

\section{Tercera}

Las probetas de mortero hechas con cemento 1 y con sus mezclas con escoria y con ceniza volante $\mathrm{EN}-1$-sumergidas en las disoluciones de $\mathrm{MgSO}_{4} .7 \mathrm{H}_{2} \mathrm{O}$, cuyas concentraciones de iones $\mathrm{SO}_{4}$ (II) y Mg (II) son $\geq 50,200$ e $\geq$ $\geq 12,720 \mathrm{~g} / \mathrm{l}$, respectivamente- experimentan un ataque superficial desde las primeras edades y, de un modo especial, las probetas elaboradas con las mezclas que tienen las mayores cantidades de escoria o de ceniza volante llegando a desintegrarse, conforme se incrementa el tiempo de conservación-ataque.

Fotografía 10.-(Fot. 10.1. y Fot. 10.2.). Laguna de Pétrola (Albacete). Vista de una probeta. 


\title{
7. BIBLIOGRAFÍA
}

(1) GASPAR-TEBAR, D. (1981): Durabilidad del hormigón. Programa de Investigación del IETcc. Informes de la Construcción, 330, 41-50.

(2) BERMEJO-MUÑOZ, M. ${ }^{a}$ F.; SAGRERA-MORENO, J. L. y GASPAR-TEBAR, D. (1986): Resistencia quimica del hormigón XXVII. Contribución al estudio del sistema: cemento P-550-ARI hidratado-agua desionizada. Materiales de Construcción, 205, 37-47.

(3) BERMEJO-MUÑOZ, M. ${ }^{a}$ F.; SAGRERA-MORENO, J. L. y GASPAR-TEBAR, D. (1987): Resistencia quimica del hormigón XXVIII. Contribución al estudio del sistema: cemento P-550-ARI hidratado-disolución de sulfato de sodio. Materiales de Construcción, 206, 61-70.

(4) GASPAR-TEBAR, D.; SAGRERA-MORENO, J. L. y BERMEJO-MUÑOZ, M. ${ }^{a}$ F. (1988): Resistencia quimica del hormigón. XXXIX. Contribución al estudio del sistema: cemento P-550-ARI hidratado-disolución de sulfato de magnesio. Materiales de Construcción, 208, 49-65.

(5) SAGRERA-MORENO, J. L. y GASPAR-TEBAR, D. (1980): Resistencia química del hormigón IV. Acción del agua de mar influencia de la adición de escoria a un cemento portland de alta resistencia inicial. Evolución de las resistencias mecánicas a flexotracción y del coeficiente de corrosión. Materiales de Construcción, 178, 17-38.

(6) GASPAR-TEBAR, D. y SAGRERA-MORENO, J. L. (1981): Resistencia química del hormigón. IX. Influencia de la adición de escoria a un cemento portland de alta resistencia inicial. Estudio por DRX del sistema: cemento 1/escoria-agua potable filtrada. Materiales de Construcción, 181, 33-44.

(7) GASPAR-TEBAR, D. y SAGRERA-MORENO, J. L. (1982): Resistencia química del hormigón. XVI. Acción del agua de mar: influencia de la adición de escoria a un cemento portland de alta resistencia inicial. Estudio por DRX. Materiales de Construcción, 186, 39-60.

(8) GASPAR-TEBAR, D. y SAGRERA-MORENO, J. L. (1984): Resistencia química del hormigón. XXII. Influencia de la adición de escoria a un cemento portland de alta resistencia inicial. Estudio de la concentración iónica del sistema: cemento 1/escoria-agua de mar artificial. Materiales de Construcción, 193, 51-68.

(9) GARCIA DE PAREDES, P. (1967): Inalterabilidad de los conglomerantes al ataque de los sulfatos. Comparación de métodos para apreciarla. Cuadernos de Investigación del IETcc (Madrid), pp. 11-14.

(10) RIEDEL, W. (1973): Die Korrosionsbeständigkeit von Zementmörteln in Magnesiumsalzlösungen. Zement-Kalk-Gips, 6, 286-296.

\section{AGRADECIMIENTO}

Nuestro más sincero agradecimiento a las personas del El "Durabilidad del Hormigón" del ICCET: Amalia Rodríguez Pereira, Lucila López Solana, M. ${ }^{a}$ Soledad Cid Fernández, Felipe Cantero Palacios y Manuel Cantero Palacios por su valiosa colaboración en la realización de este trabajo.

\section{publicación del ICCET/CSIC}

\author{
INSPECCION DE OBRAS DAÑADAS \\ POR CORROSION DE ARMADURAS
}

El presente Manual va dirigido principalmente a técnicos especializados y laboratorios que tienen que intervenir en el dictamen de la situación de deterioro de estructuras de hormigón armado dañadas por corrosión de armaduras.

Comienza con un resumen recordatorio de los factores principales a los que se pueden deber los daños prematuros por corrosión de armaduras, para seguir con algunas indicaciones de cómo se deben realizar las inspecciones, y de los ensayos y la metodología que se recomienda realizar para poder dictaminar con precisión las causas de daño.

A continuación se hacen una serie de comentarios sobre la vida residual de estructuras dañadas, sobre el riesgo de corrosión futura, el seguimiento necesario de una estructura reparada y una breve enumeración de métodos de reparación y consideraciones básicas a tener en cuenta en la recomendación de un determinado método. Se aporta una breve relación bibliográfica.

Finalmente se incluyen en forma de ficha la descripción de algunos casos de corrosión de armaduras detectados en nuestro país.

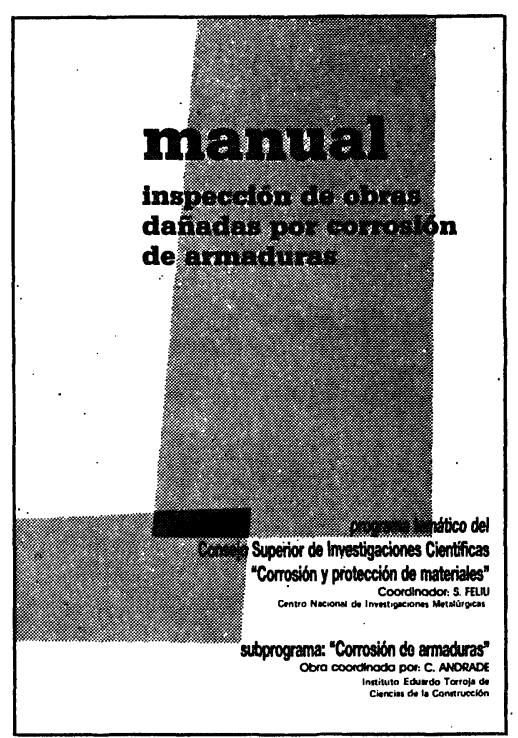

